\title{
Interactions between the stratospheric polar vortex and Atlantic circulation on seasonal to multi-decadal timescales
}

\author{
Oscar Dimdore-Miles ${ }^{1}$, Lesley Gray ${ }^{1,2}$, Scott Osprey ${ }^{1,2}$, Jon Robson ${ }^{2,3}$, Rowan Sutton ${ }^{2,3}$, and \\ Bablu Sinha ${ }^{4}$ \\ ${ }^{1}$ Atmospheric, Oceanic and Planetary Physics, Department of Physics, University of Oxford, OX1 3PU, UK \\ ${ }^{2}$ National Centre for Atmospheric Science \\ ${ }^{3}$ Department of Meteorology, University of Reading, Reading, RG6 6ET \\ ${ }^{4}$ National Oceanography European Way, Southampton SO14 3ZH
}

Correspondence: Oscar Dimdore-Miles (oscar.dimdore-miles@physics.ox.ac.uk)

\begin{abstract}
.
Variations in the strength of the Northern Hemisphere winter polar stratospheric vortex can influence surface variability in the Atlantic sector. Disruptions of the vortex, known as sudden stratospheric warmings (SSW), are associated with an equatorward shift and deceleration of the North Atlantic jet stream, negative phases of the North Atlantic Oscillation as well as cold snaps over Eurasia and North America. Despite clear influences at the surface on sub-seasonal timescales, how stratospheric vortex variability interacts with ocean circulation on decadal to multi-decadal timescales is less well understood. In this study, we use a 1000-year pre-industrial control simulation of the UK Earth System Model to study such interactions using a wavelet analysis technique to examine non-stationary periodic signals in the vortex and ocean. We find that intervals which exhibit persistent anomalous vortex behaviour lead to oscillatory responses in the Atlantic Meridional Overturning Circulation (AMOC). The origin of these responses appears to be highly non-stationary with spectral power in vortex variability and the AMOC at periods of 30 and 50 years. In contrast, AMOC variations on longer timescales (near 90-year periods) are found to lead to a vortex response, through a pathway involving the equatorial Pacific and Quasi-biennial Oscillation. Using the relationship between persistent vortex behaviour and the AMOC response established in the model, we use a regression analysis to estimate the potential contribution of the 8 year SSW hiatus interval in the 1990s to the recent negative trend in AMOC observations. The result suggests that approximately $30 \%$ of the trend may have been caused by the SSW hiatus.
\end{abstract}




\section{Introduction}

Variations in the strength of the Northern Hemisphere (NH) stratospheric polar vortex associated with sudden stratospheric warming (SSW) events is the single largest source of interannual variability in the NH winter stratosphere. Extreme disruptions of the vortex during SSWs also represent a key mechanism for stratosphere-troposphere coupling and are widely acknowledged to lead to anomalies in NH mid-latitude surface climate, particularly in the North Atlantic sector (Baldwin and Dunkerton, 2001). Equally, the absence of an SSW, when the vortex is relatively undisturbed by waves propagating from the troposphere so that the vortex is unusually strong and cold, also has significant impacts on surface weather (Shaw and Perlwitz, 2013; Lawrence et al., 2020). An understanding of SSW dynamics and vortex variability is therefore important for seasonal to subseasonal forecasting of surface weather (Domeisen et al., 2020a, b) as they provide a significant source of predictive skill. The majority of studies that have examined the associations between the stratospheric polar vortex and surface anomalies have considered their in-season impact. However, the NH winter stratosphere also exhibits variability on decadal to multidecadal timescales (Dimdore-Miles et al., 2021). The interaction between this low-frequency variability in vortex strength and variations in surface climate on similar timescales is not fully understood.

The impact of stratospheric polar vortex (hereafter referred to as 'the vortex') variations on surface climate variability was highlighted in the seminal work of Baldwin and Dunkerton (2001) which demonstrates a steady downward propagation of Northern Annular Mode (NAM) anomalies from the middle stratosphere to the surface following strong and weak vortex events in the ERA40 reanalysis dataset. The anomalies associated with a weak (strong) vortex were shown to persist at the surface intermittently for approximately 60 days after the event and projected significantly onto the negative (positive) pattern of the North Atlantic Oscillation (NAO). Subsequent modelling and observational studies have corroborated these results: Domeisen (2019) show, using ERA40 and ERA-Interim datasets, that approximately two-thirds of SSW events are followed either by a switch from positive to negative NAO or a persistent negative NAO pattern. Charlton-Perez et al. (2018) consider this coupling from the perspective of tropospheric weather regimes and find, in both ERA-Interim and the ECMWF Integrated forecast model, a 40-60\% increase in probability of transition to a negative phase of the NAO given a one standard deviation reduction in polar vortex strength. This SSW influence on the NAO is relatively well represented in GCMs (Baldwin et al., 2021) and idealised modelling studies are also able to show a direct downward influence of events on the NAO (White et al., 2020; Gerber et al., 2009), although some studies have noted that simple models tend to over-represent the persistence of surface anomalies (Gerber et al., 2008a, b),

The influence of SSW events on negative NAO phase probability has subsequently been shown to influence other features of NH mid-latitude climate. Thompson et al. (2002) show in NCEP-NCAR reanalysis that SSWs are followed by a 60 day interval of anomalously low surface temperatures in eastern North America, northern Europe, and eastern Asia. Subsequent observational studies find similar response patterns to SSWs (Kolstad et al., 2010; King et al., 2019; Lehtonen and Karpechko, 2016) and the effect can also be seen in GCM simulations (Tomassini et al., 2012; Lehtonen and Karpechko, 2016). Further impacts of SSWs on tropospheric circulation include an equatorward shift and deceleration of the North Atlantic eddy-driven jet stream (Hitchcock and Simpson, 2014; Maycock et al., 2020). Links with persistent blocking events are also shown in 
observations and modelling studies (Davini et al., 2014; Vial et al., 2013) although Taguchi (2008) finds no significant link between the phenomena.

While the in-season influence of SSWs on tropospheric circulation and surface variability is discussed extensively in previous work, their coupling with modes on longer timescales such as ocean variability is less well understood. One of the primary features of Atlantic Ocean variability is the Atlantic Meridional Overturning Circulation (AMOC) which consists of a northward transfer of warm, saline water that occurs in the top $2 \mathrm{~km}$ of the Atlantic Ocean (the "upper cell") accompanied by a corresponding return flow of southward transport at lower depths (the "lower cell") (Kuhlbrodt et al., 2007; Xu et al., 2014; Buckley and Marshall, 2016). The strength of the AMOC varies significantly on decadal-centennial timescales (Delworth et al., 1993; Biastoch et al., 2008; Tulloch and Marshall, 2012; Menary et al., 2012) and is thought to be a key driver of North American and European surface variability via modulation of Atlantic sea surface temperatures (SSTs) and heat transport (Knight et al., 2005; Delworth and Mann, 2000; Frierson et al., 2013; Frankignoul et al., 2013). It has been shown to influence a diverse range of features such as European summertime temperatures (Sutton and Hodson, 2005), biogeochemical conditions in the northwest Atlantic (Lavoie et al., 2019) as well as abrupt climate shifts in paleoclimate records (Alley, 2007; Cheng et al., 2009).

Multiple potential drivers of AMOC variability at different timescales have been studied extensively in both observations and modelling studies. On intra-annual to inter-annual timescales, variability in the AMOC has been closely associated with wind variations over the North Atlantic region through Ekman-transport anomalies or wind stress curl forcing (Wang et al., 2019; McCarthy et al., 2012; Mielke et al., 2013; Yang, 2015). On inter-annual to decadal timescales, AMOC variability has been associated with buoyancy anomalies in the subpolar region, particularly in the Labrador Sea (Delworth et al., 1993; Medhaug et al., 2012). This mechanism is linked to variability in mixed layer depth and the occurrence of deep convection over the same region, particularly in NH winter (Böning et al., 2006; Biastoch et al., 2008; Robson et al., 2012; Wang et al., 2015). Mixed-layer anomalies in the Labrador Sea are an indication of the strength of deep convection in this region, which has been shown to be associated with AMOC variations in modelling studies (Eden and Willebrand, 2001; Eden and Jung, 2001) and observations (Latif and Keenlyside, 2011).

An association between stratospheric polar vortex variability and the AMOC on decadal timescales has been previously investigated (Reichler et al., 2012; Schimanke et al., 2011) but the mechanism of its influence remains unclear. For example, Reichler et al. (2012) examine the response of the AMOC to strong and weak polar vortex events and show a lagged, oscillatory response in the AMOC. They propose a pathway involving alterations of wind stress and ocean-atmosphere heat flux anomalies in the West Atlantic due to the changed NAO patterns following the vortex events. The effect is prominent in a pre-industrial (PI) control of a single model (GFDL-CM2.1) and to some extent in a suite of CMIP5 models. An impact of long-term changes in the NAO on the strength of the AMOC is supported by a number of studies (Visbeck et al., 1998; Delworth and Dixon, 2000; Delworth and Greatbatch, 2000; Eden and Willebrand, 2001; Lohmann et al., 2009; Robson et al., 2012). Most recently Delworth and Zeng (2016) used a set of idealised GCM experiments in which they impose a perpetual ocean-atmosphere heat flux pattern associated with different NAO phases. They find significantly different AMOC mean states depending on the imposed pattern (a stronger AMOC under positive NAO flux conditions than a control simulation). Haase et al. (2018) also 
analysed the in-season influence of SSW events on the NAO and ocean-atmosphere heat fluxes that then impacts the strength of deep convection in the North Atlantic, using the CESM1 WACCM model. The study notes the presence of an anomalously shallow mixed layer depth in the Labrador Sea following an SSW event.

A key result from Reichler et al. (2012) is the decadal modulation of the SSW-AMOC co-variability. However, decadal to multi-decadal variability in vortex strength is not well understood. Some studies have focused on potential polar vortex impacts at the surface but suffer from low statistical significance due to the short observational record. Garfinkel et al. (2017), Garfinkel et al. (2015) and Cohen et al. (2009) link decadal fluctuations in vortex strength with modulation of the global warming signal in Eurasian surface temperature in both reanalyses and CMIP3 models. Schimanke et al. (2011) demonstrate multi-decadal signals in SSW occurrence in a multi-century GCM simulation and propose an influence of these signals on similar period variability in Eurasian snow cover and Atlantic SSTs. However, results from this study are difficult to interpret as the GCM used (EGMAM: ECHO-G with Middle Atmosphere Model) exhibits significant bias in its vortex representation with a mean SSW rate of only 2 events per decade compared to 6 events per decade in most reanalyses (Ayarzagüena et al., 2019). They note that repeating their study with a more advanced model is required to corroborate their findings. Manzini et al. (2012) examined decadal fluctuations in SSW events in a 260 year prescribed SST simulation of a GCM and analyse their impacts at the surface. They show that decadal vortex variability excites similar timescale variations in surface temperature and sea ice coverage between Greenland and Norway over the Atlantic sector. They propose this connection to be indicative of a delayed response of the AMOC to stratospheric forcing via the NAO which subsequently influences northward Atlantic heat transfer and sea ice melt rates as well as surface temperatures anomalies.

More recently, Dimdore-Miles et al. (2021) (henceforth referred to as DM21) examined long-term variability in the strength of the winter polar stratospheric vortex in a 1000-yr PI control simulation of the UK Earth System Model. They identified sequences of up to 11 consecutive years in which at least one SSW occurred every year (similar to that observed during the period 1998-2004) and also sequences of up to 12 consecutive years with a strong undisturbed vortex as was observed during the 1990s (Manney et al., 2005; Pawson and Naujokat, 1999). They identified multi-decadal signals of 90-year periodicity in the latter that persisted for approximately 450 years of the 1000 years. Using wavelet and cross-spectral analysis, they associated this with a similar signal in the amplitude modulation of the Quasi Biennial Oscillation (QBO) and proposed that the vortex variability was driven by the QBO through modulation of the Holton-Tan relationship (Lu et al., 2008, 2014). However, the focus of that paper was primarily in the stratosphere, identifying and understanding the relationship between the long-term QBO and vortex variability. In this paper, we use the same 1000-yr pi-control simulation to extend that study to examine the links between long-term vortex variability and the North Atlantic including oceanic modes. We first examine the near-surface in-season response to extreme vortex events to demonstrate that the model is able to reproduce corresponding anomalies in mean sea level pressure (MSLP), ocean-atmosphere heat flux and SSTs consistent with previous studies. We then explore the response on multi-decadal timescales using a wavelet analysis method to examine non-stationary signals in the vortex and the AMOC variability. We find that multi-year intervals which exhibit the same type of persistent, anomalous vortex behaviour also exhibit co-variability with the AMOC across multiple timescales. The interactions and feedback mechanisms on these different timescales are explored in more detail using a combination of lag/lead composite analysis as well as wavelet spectral 
decomposition method. The amplitude and lag of the AMOC response to a multi-year period of strong polar vortex in the model is determined. This is then used to estimate the potential contribution of the observed 8 consecutive years with a very stable, undisturbed stratospheric vortex in the 1990s (Pawson and Naujokat, 1999) to the recent observed negative trend in the strength of the AMOC. The paper is structured as follows: Section 2 describes the GCM used in the investigation, the spectral analysis method (wavelet analysis) and the relevant climate indices. Section 3 presents results from the analysis. Section 4 provides a summary and discussion of the results.

\section{Data and Methods}

\subsection{Model Configuration}

This work utilises the same model as that analysed in DM21, The first version of the UK Earth System Model (henceforth referred to as UKESM). UKESM is a stratosphere resolving coupled ocean-atmosphere-land-sea ice model. It contains 85 vertical levels in the atmospheric domain simulated by the Global Atmosphere 7.1 component (GA7.1) 35 of which lie above $35 \mathrm{~km}$ in altitude (Walters et al., 2019; Williams et al., 2018). GA7.1 runs at N96 horizontal resolution ( $135 \mathrm{~km}$ at the equator). Ocean circulation is simulated by GO6.0 (Storkey et al., 2018) which contains 75 vertical levels and runs at $1^{\circ}$ horizontal resolution. Additional interactive components simulating land surface, sea ice and atmospheric chemistry processes are added via coupling with JULES (GL7.0), CICE (GSI8.1) and UK Chemistry and Aerosols (UKCA) models respectively (Walters et al., 2019; Ridley et al., 2018; Mulcahy et al., 2018). The model's representation of the North Atlantic Climate system has been examined previously by Robson et al. (2020); this study shows that UKESM is able to realistically simulate key features such as the AMOC. However, this study highlights the model's under-representation of variability in the AMOC, an issue which is reported in other physical models (Roberts et al., 2014).

We utilise the same 1000 year PI control simulation as examined in DM21. This simulation is spun-up to achieve model equilibrium before initialising following the method outlined in Yool et al. (2020). The run is forced using CMIP6 pre-industrial values for concentrations of major GHGs (global mean 284.317ppm $\mathrm{CO}_{2}, 808.25 \mathrm{ppb} \mathrm{CH}_{4}, 273.02 \mathrm{ppb} \mathrm{N}_{2} \mathrm{O}$ ). There are no volcanic eruptions in the simulation but a background stratospheric volcanic aerosol level is imposed using climatological values between 1850 and 2014 estimated from satellite products and other model simulations (Menary et al., 2018). The simulation does not exhibit a solar cycle. We choose to analyse a pi-control simulation due to the length of integration performed (1000 years) compared to the timescales of stratospheric variations shown in DM21 (near 90-year variability). This length of simulation provides a greater number of possible cycles of such variability available for analysis compared to the use of a historical simulation. Furthermore, a pi-control allows us to analyse the internal variability of the stratosphere.

To estimate the contribution of stratospheric variations to recent observed AMOC trends we also make use of observationbased datasets of the atmosphere and oceans. First, we utilise the reanalysis data from the European Centre for Medium-Range Weather Forecasts (ECMWF): ERA5 (Hersbach et al., 2020) for assimilated observations for geopotential height (GPH) and MSLP fields downloaded from https://climate.copernicus.eu/climate-reanalysis (last accessed 10/08/21). Second, the Rapid Array Dataset which provides time-depth profiles for the meridional overturning mass streamfunction in the Atlantic region at 
$26^{\circ} \mathrm{N}$ (Moat et al., 2020). These data are measured through a combination of ocean mooring, ship-based, satellite and submarine telephone cable observations to estimate the strength of primary contributions to the meridional overturning circulation: Ekman transport (through wind stress), transport through the Florida Straits and transport driven by East-West density gradients between the American and African continents (McCarthy et al., 2015).

\subsection{Wavelet Analysis}

We employ the same wavelet analysis method as DM21 based on Torrence and Compo (1998) to examine potential nonstationary spectral characteristics of time series data over a range of periods. This method is outlined in full in section 2.3 of DM21 and is reproduced briefly here.

The wavelet transform of a 1-dimensional time series, $x$, of length $N$ and uniform timestep $\delta t$ is given by the convolution between the series and a wavelet function $\psi$ which has been scaled by the quantity $s$,

$W_{n}(s)=\sum_{n^{\prime}=0}^{N-1} x_{n^{\prime}} \psi^{*}\left[\left(n^{\prime}-n\right) \frac{\delta t}{s}\right]$,

where $s$ is the scale of the wavelet which indicates its period and $n$ is the time index. Varying $s$ and translating along the time axis builds up a power spectrum for $x$ in the time-period domain given by $\left|W_{n}(s)\right|^{2}$. Following Torrence and Compo (1998) we vary the scale parameter in increasing powers of 2 such that $s_{j}=s_{0} 2^{j \delta j}$ and $j=0,1, \ldots, J$, where $j$ is the index for the wavelet scale, $s_{0}$ is the smallest resolvable scale for the series and $J$ is the index corresponding to the largest scale given by

$J=\delta j^{-1} \log _{2}\left(\frac{N \delta t}{s_{0}}\right)$

The translated and scaled wavelet evaluated at a given scale, $s$, has the form

$\psi^{*}\left[\left(n^{\prime}-n\right) \frac{\delta t}{s}\right]=\left(\frac{\delta t}{s}\right)^{1 / 2} \psi_{0}\left[\left(n^{\prime}-n\right) \frac{\delta t}{s}\right]$

and we select the form of the wavelet basis function $\psi_{0}$ following the recommendation of Torrence and Compo (1998) as a Morlet wavelet, an oscillatory function enveloped by a Gaussian which is expressed as

$\psi_{0}(p)=\pi^{-1 / 4} e^{i \omega_{0} p} e^{\frac{p^{2}}{2}}$

The advantages of using a Morlet wavelet for analysing signals in climate time series is primarily due to its ability to resemble many of the features commonly observed in climate time series (e.g. changes in dominant period, and amplitudes). The full argument for this choice is presented in Lau and Weng (1995) as well as DM21. To directly compare spectra of different indices, we normalise all time series by subtracting the mean and dividing by its standard deviation before performing 
the wavelet transform. In order to effectively compare spectral power across a range of frequencies we additionally scale the power spectrum by dividing by the scale parameter ( $s_{j}$ defined above) associated with each frequency. This is done following the methodology of Liu et al. (2007) which shows that un-scaled spectra exhibit a bias towards overestimated powers at longer periods and that an effective comparison across timescales is possible with such scaling. We also define a confidence interval for wavelet power observed for the series $x$ by comparing the observed power to that produced by a time series modelled as a first-order auto-regressive (AR1, red noise) process, $r$, given by

$r_{n}=\alpha r_{n-1}+z_{n}$

where $\alpha$ is the lag-1 autocorrelation of $x$ and $z_{n}$ is a Gaussian white noise term. Torrence and Compo (1998) show that the power spectrum of this is $\chi^{2}$ distributed and therefore can be used to define a $95 \%$ confidence interval for any observed power.

\subsection{Cross Wavelet Spectra}

We also define a measure of coincident spectral power between two time series, the cross wavelet spectrum. This metric indicates whether two series exhibit power at the same timepoints and frequencies. The cross wavelet spectrum of two time series $x$ and $y$ with associated wavelet spectra $W_{n}^{x}$ and $W_{n}^{y}$ is calculated by projecting one spectrum onto the other:

$\left|W_{n}^{x y}(s)\right|=\left|W_{n}^{x *}(s) W_{n}^{y}(s)\right|$,

where $W_{n}^{x *}(s)$ is the complex conjugate of the wavelet power spectrum of $x$ (Grinsted et al., 2004). The complex argument of $W_{n}^{x y}(s)$ gives the local phase difference between signals in $x$ and $y$ in frequency-time space. The phase relationship between the two time series can be represented by a vector that subtends an angle representing the phase difference in radians: On all plots of cross spectra, arrows to the right (left) denotes signals in the two series which are in-phase and correlated (anticorrelated). Vertical arrows indicate a phase relationship of $\frac{\pi}{2}$ between the time series, so that the evolution of one is correlated with the time rate-of-change of the other. As for individual power spectra, we define a confidence interval for which cross power of a larger amplitude is deemed significant ( $>95 \%$ confidence interval) by comparing power exhibited by actual series with a theoretical red noise process. The cross power of two such AR1 processes is theoretically distributed such that the probability of obtaining cross power greater than a set of red-noise processes is

$D\left(\frac{\left|W_{n}^{x y}(s)\right|}{\sigma_{x} \sigma_{y}}<p\right)=\frac{Z_{\nu}(p)}{\nu} \sqrt{P_{k}^{x} P_{k}^{y}}$ 
where $\sigma$ denotes the standard deviation of the time series, $Z$ is the confidence interval defined by $p$ ( $Z=3.999$ for $95 \%$ confidence), $\nu$ is the degrees of freedom for a real wavelet spectrum $(\nu=2)$ and $P_{k}^{x}$ is the theoretical Fourier spectrum of the AR1 process. For a given wavenumber $k$ and given by

\subsection{Model Diagnostics}

We utilise the Northern Annular Mode (NAM) as a metric for the strength of the vortex as used by Baldwin and Dunkerton (2001) as well as numerous subsequent studies. The NAM is defined as the 1st principal component (PC) of the zonal mean, deseasonalised geopotential height field evaluated at latitudes north of $20^{\circ} \mathrm{N}$ over the $\mathrm{NH}$ winter season (Dec-Mar) on a given pressure level. To measure the vortex strength we evaluate the NAM at $10 \mathrm{hPa}$ which is the pressure level used to identify major SSWs, and the resulting index is henceforth known as $\mathrm{NAM}_{10}$. An individual vortex event (either strong or weak) is recorded when the daily $\mathrm{NAM}_{10}$ crosses a threshold of +1.5 (strong) or -2 (weak). The day on which this reversal occurs is referred to as the central date. After this date, the $\mathrm{NAM}_{10}$ must recover to westerly for at least 10 consecutive days (which is the approximate radiative timescale of the mid-stratosphere) before another event can be recorded. The strong threshold value for events is chosen in accordance with the methodology of Baldwin and Dunkerton (2001) and the weak threshold selected such that it results in approximately the same rate of weak events (SSWs) as is reported in DM21 using the same simulation of UKESM but with a zonal wind definition of SSWs (0.54 events/winter).

We also use the $\mathrm{NAM}_{10}$ to derive an index for the appearance of intervals of consecutive winters which show persistent vortex behaviour. The persistent $\mathrm{NAM}_{10}$ interval index is defined as follows: First, the $\mathrm{NAM}_{10}$ is averaged over each $\mathrm{NH}$ winter season (December-March), this gives a measure of mean vortex strength for each winter. Second, this index is smoothed using a Gaussian filter which is carried out through a convolution of the time series with a 1D Gaussian kernel in the time domain given by

$f(t, \sigma)=\frac{1}{\sqrt{2 \pi \sigma^{2}}} e^{-\frac{1}{2}\left(\frac{t}{\sigma}\right)^{2}}$

where $\sigma$ is the standard deviation of the distribution defined by the kernel. We choose $\sigma=2$ years following the method of

Reichler et al. (2012) and as a method analogous to the 5-year smoothing applied to an SSW time series in DM21. The selection of $\sigma=2$ years allows contributions to the smoothed value from values approximately 7 years either side of the central year as the value of the Gaussian window decays to near 0 approximately $3.5 \sigma$ from its mean. However, the largest contributions come from 3-4 years either side of the central year. This allows the smoothing to capture instances of $\sim 6-8$ consecutive years with persistent vortex behaviour, a similar length to intervals observed in reanalysis (e.g. the 1990s, Pawson and Naujokat (1999)).

We subsequently define persistent $\mathrm{NAM}_{10}$ intervals, when the vortex exhibits the same type of behaviour for a number of consecutive years, using extreme values of the smoothed $\mathrm{NAM}_{10}$ index. A persistent $\mathrm{NAM}_{10}$ interval is recorded when the smoothed $\mathrm{NAM}_{10}$ index value falls within the top 5 percentile values. Once such an interval occurs, another cannot be 
recorded for 15 years after to avoid choosing multiple central years within the same interval. Using 5 percentile values gives approximately the same rate of persistent vortex intervals as is reported in Reichler et al. (2012) so we proceed with this threshold throughout for a direct comparison with this study. Tests were also carried out to assess the sensitivity of our results to this threshold and are reported in section 3.

We define an AMOC index following the procedure in Reichler et al. (2012). The AMOC is defined using the overturning streamfunction field in the Atlantic sector. At each time point, the AMOC index is the maximum streamfunction value at any depth at a chosen latitude. We evaluate the index at $30 \mathrm{~N}, 45 \mathrm{~N}$ and $50 \mathrm{~N}$ and measure the response and co-variability with the $\mathrm{NAM}_{10}$ time series and other climate indices defined below. We derive the observed AMOC index from the Rapid Array data as the maximum MOC at each time point at $26 \mathrm{~N}$. We also utilise a definition of the North Atlantic Oscillation from Hurrell et al. (2003). The NAO index is defined as the $1 \mathrm{st}$ PC of the Dec-Mar MSLP in the region $20^{\circ}-80^{\circ} \mathrm{N}, 90^{\circ} \mathrm{W}-40^{\circ} \mathrm{E}$. The PC is calculated by taking the first empirical orthogonal function (EOF) of deseasonalised MSLP anomalies and projecting this EOF onto the anomaly field. We additionally derive an Ocean-Atmosphere heat flux field defined as the sum of latent and sensible heat fluxes between the ocean surface and the atmosphere (i.e. positive values indicate the exchange of heat from the ocean to the atmosphere). We derive an index for the occurrence of deep convection anomalies in the equatorial eastern Pacific region. This index is defined by the top of atmosphere outgoing longwave radiation (OLR) averaged over the box $10^{\circ} \mathrm{S}-10^{\circ} \mathrm{N}$, $240^{\circ}-290^{\circ} \mathrm{E}$. The OLR field is utilised as it acts as a proxy for the occurrence of convection anomalies - When deep convection is enhanced, cloud top height is increased and therefore OLR is reduced. The East Pacific box is selected following a sensitivity analysis to establish the region which exhibits 90-year timescales variations in OLR. It is also a similar region to studies that consider east pacific ENSO patterns which is identified as a separate mode of variability to the traditionally used central pacific ENSO region (Johnson, 2013).

We also utilise the same QBO metric as in DM21. This is defined as the Zonal Mean Zonal Wind (ZMZW) averaged over the latitude range $5^{\circ} \mathrm{S}-5^{\circ} \mathrm{N}$, and the pressure level range $15-30 \mathrm{hPa}$. This metric captures the degree of vertical coherence in the QBO, an attribute shown to be important for QBO teleconnections with the NH mid-latitudes (Andrews et al., 2019). Following the method of DM21 we also define the instantaneous amplitude of the deep QBO, which exhibits significant modulation in the westerly phase (see DM21 figures 10 and 11), using the Hilbert transform of the QBO $(H i l[Q B O(t)])$ defined as

$\operatorname{Hil}[Q B O(t)]=\frac{1}{\pi t} * Q B O(t)$

where $*$ signifies a convolution and $t$ is discretised time. The time varying Amplitude, $A(t)$, can then be expressed in terms of $Q B O(t)$ and $H i l[Q B O(t)]$ such that

$Q B O(t)+H i l[Q B O(t)] i=A(t) e^{i \theta}$,

where $\theta(t)$ is the instantaneous phase angle - a measure of signal progression through a cycle at time $t$.

Finally, We analyse the relationship between the magnitude of smoothed stratospheric $\mathrm{NAM}_{10}$ extremes and 17-year lagged AMOC anomalies using linear regression with a single predictor (the lagged AMOC). We analyse the strength of linear rela- 
tionship using a correlation coefficient, $r$, and estimate a significance level for this value using a bootstrapping which assesses the probability such a value results if the phases in signals in the NAM 10 and AMOC are randomly assigned but the overall autocorrelation structure is retained. We do this by comparing the $r$-value calculated with real data with those produced from a set of synthetic $\mathrm{NAM}_{10}$ series. These synthetic data are generated by applying a Fourier transform to the smoothed $\mathrm{NAM}_{10}$ index, randomly shuffling the Fourier phases and subsequently inverse Fourier transforming to generate a surrogate time series with the same Fourier power spectrum as the real data. Repeating this data generation and calculating the correlation between the magnitude of positive extremes in the surrogate $\mathrm{NAM}_{10} \mathrm{~s}$ and the 17 year lagged AMOC builds up a PDF for the $r$ value which can be used to estimate the significance level for a real $r$ value.

\section{Results}

\subsection{In-season surface responses to anomalous polar vortex events}

We begin by diagnosing the in-season response to anomalous vortex events exhibited by surface variability in the model to assess its suitability for studying interactions on longer timescales. Figure 1 shows the mean sea level pressure (MSLP) composite differences between strong and weak polar vortex years (figure 1, top row). The composites have been determined by selecting MSLP values associated with events in which the daily $\mathrm{NAM}_{10}$ values cross the +1.5 (strong) or -2 (weak) threshold (see section 2.4). The composite differences demonstrate a significant lagged MSLP response, with strong (weak) vortex years corresponding to a positive (negative) NAO pattern, in agreement with previous modelling and observational studies (see section 1). The NAO anomalies peak in magnitude at a lag of 1-2 months following the vortex anomalies with significant anomalies still visible for up to 3 months. There is also a weak positive NAO pattern that leads the vortex anomalies by up to one month ( $-1-0$ month lags). This may be an indication that an anomalous NAO pattern is a precursor for an anomalous vortex, or it could be a response to the initiation of the vortex anomaly since this usually commences in the upper stratosphere and pre-dates the event's central date defined at $10 \mathrm{hPa}$. Further exploration of this weak NAO signal is outside the scope of this paper. Additionally, a much stronger significant positive anomaly over the Aleutian low (AL) region is evident in the month leading up to the vortex anomaly. This signal has been widely studied (Rao et al., 2019) and links the intensity of the AL to the strength of vertically propagating planetary waves that subsequently interact with the stratospheric vortex and influence its strength. DM21 examined this coupling using the same pi-control simulation as presented here and found a similar statistically significant relationship between the AL and the frequency of SSWs but the regression coefficients were small in comparison with the QBO influence. Here the association between the AL and the vortex strength appears marginally stronger $(r=0.39$ with the NAM) which may be due to the NAM's ability to capture both types of vortex anomalies (strong and weak). In the same study, DM21 found that the AL exhibited minimal decadal to multi-decadal variability that was coherent with the decadal to multi-decadal variability of the vortex and for this reason, the role of the AL is not considered in detail in this study. 

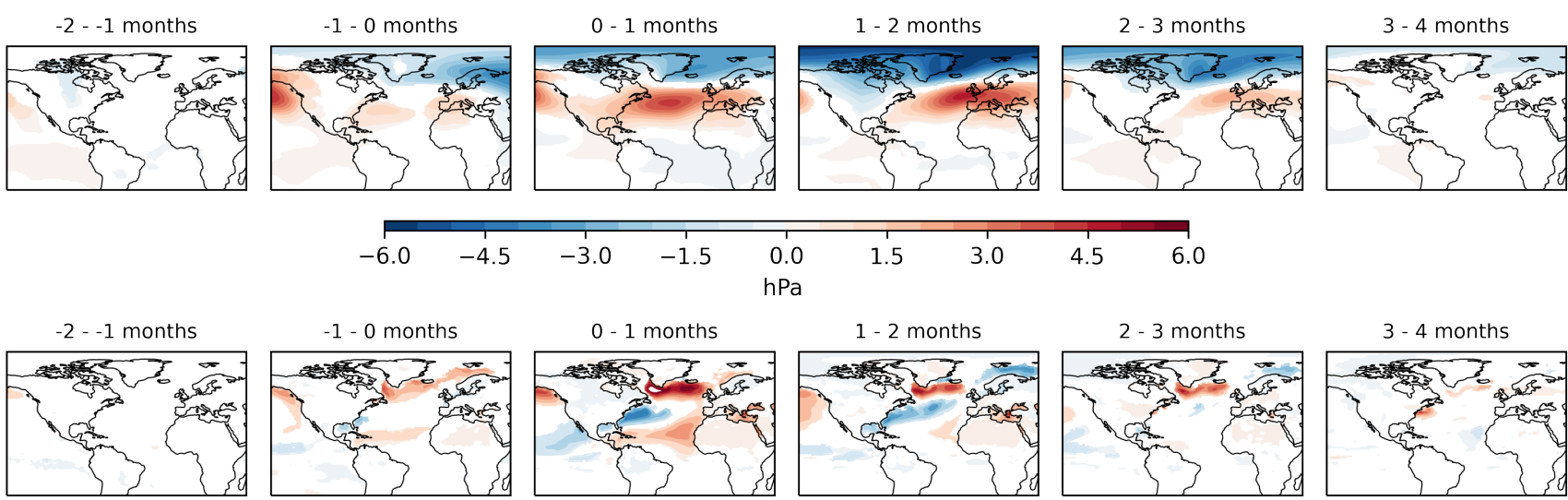

-2 - -1 months

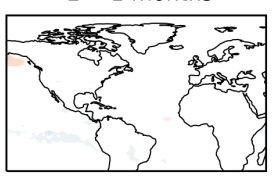

0 - 1 months

(1)
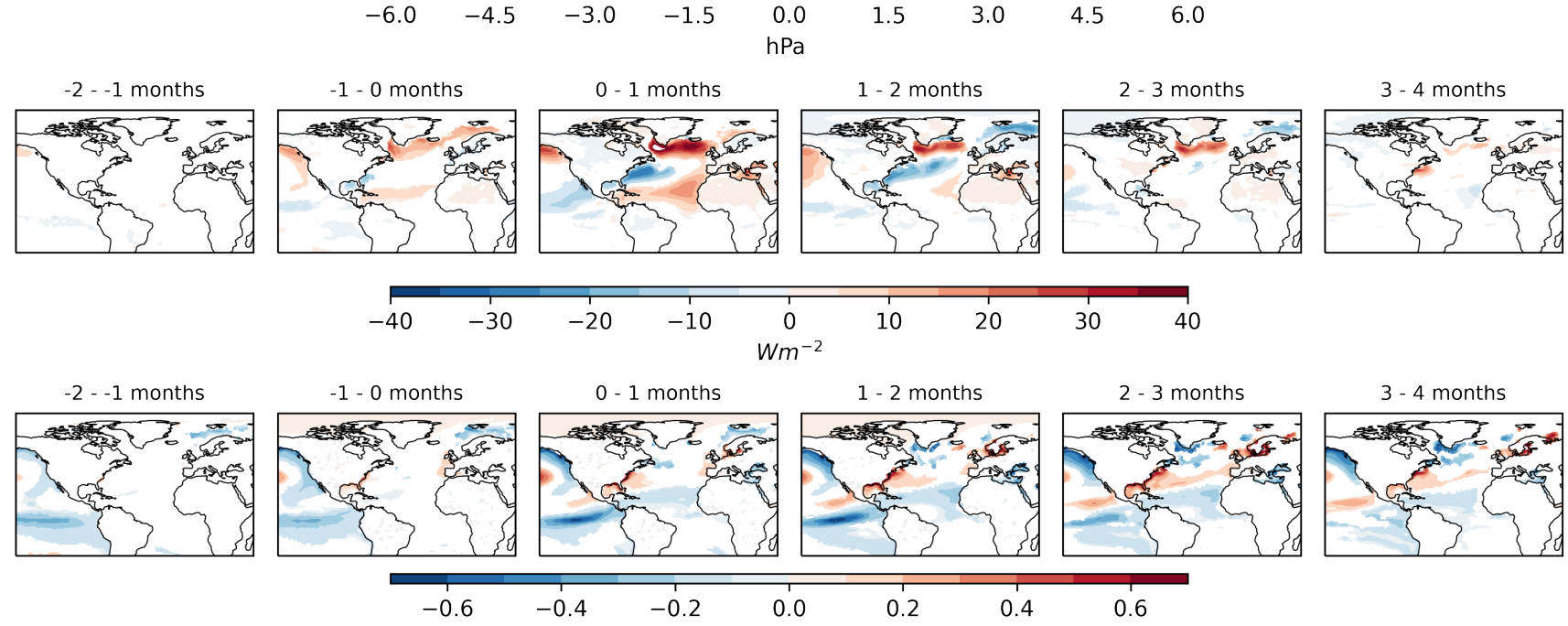

$-0.4$

$-0.2$

0.0
$K$

0.2

0.4

0.6

Figure 1. Surface patterns associated with anomalous winter stratospheric NAM $\mathrm{N}_{10}$ events. Top row: Monthly mean sea level pressure anomaly $(\mathrm{hPa})$, middle row: Ocean-Atmosphere heat flux defined as the sum of latent and sensible heat fluxes $\left(w m^{-2}\right)$ and bottom row: SSTs $(K)$. Coloured shading shows where the composite differences between strong and weak NAM 10 events are statistically significant at the $95 \%$ level under a 2 tailed students t-test. The title of each sub-figure indicates the month range relative to the central date of each $\mathrm{NAM}_{10}$ anomaly. Signals at negative times indicate that the surface anomaly leads the stratospheric NAM 10 anomaly. Signals at positive times indicate that the stratospheric $\mathrm{NAM}_{10}$ anomaly leads the surface response.

The model also exhibits significant responses in ocean-atmosphere heat flux (figure 1, middle row). The largest flux anomalies are seen within 30 days (lag 0-1 month) and their spatial pattern resembles that of a North Atlantic tripole with positive anomalies over the subpolar North Atlantic between approximately $50^{\circ}-65^{\circ} \mathrm{N}$, negative anomalies off the east coast of the USA and a second positive anomaly off the coast of North-East Africa. This pattern is consistent with the model response found by Reichler et al. (2012) to anomalous stratospheric NAM 10 events as well as the pattern associated with positive NAO phases in Delworth and Zeng (2016). As with the MSLP composites, there are visible anomalies 30 days leading up to the identified events (lag -1 - 0 months) both over the North Atlantic and Pacific regions. The Atlantic pattern may correspond to early responses to a disrupted or strengthened vortex as well as possible precursors to events. The Pacific anomalies preceding events are considerably smaller than the Atlantic anomalies and are concentrated over the Aleutian Low region. 

heat flux anomalies by around 2 months, with the largest amplitude anomalies at around 2-4 month lags. The anomaly pattern resembles that of the heat flux anomalies (with a change of sign), consistent with a mechanism in which the SSTs respond to the anomalous heat fluxes. A prominent negative tropical East Pacific anomaly is obvious in the months leading up to anomalous vortex events together with anomalies that resemble the Pacific Decadal Oscillation (PDO) in the region of the Aleutian Low (Mantua et al., 1997) and these features persist for several months. Variability in this region is dominated by El Niño Southern Oscillation (ENSO) variations and a significant body of work (e.g. Domeisen et al. (2019)) has proposed teleconnections between ENSO and vortex strength, consistent with the type of association exhibited here, i.e. negative (positive) SSTs or la Niña (el Niño) conditions associated with an anomalously strong (weak) vortex.

\subsection{Surface impacts of persistent vortex anomalies}

315 The in-season anomaly patterns associated with anomalous stratospheric $\mathrm{NAM}_{10}$ events shown in figure 1 confirm that the model can reproduce the observed influence of vortex anomalies at the surface, particularly over the Atlantic region. We now extend the analysis to examine decadal-scale variability. Following the approach of Reichler et al. (2012) we smooth the $\mathrm{NAM}_{10}$ index (figure 2) and then select the upper and lower 5 percentiles of this index to identify intervals with a persistent consecutive strong or weak polar vortex (see section 2.4 for more details). The red and blue dots on figure 2 indicate the central year of intervals identified with persistent consecutive vortex anomalies (each dot represents the centre of intervals of approximately 8 years, see section 2.4). Characteristic surface responses associated with these intervals are then analysed by compiling composites surrounding the central year of each positive and negative interval at lags of -40 (before the intervals) and 40 (after intervals) years. Calculating the (positive minus negative) composite difference can then be used to assess the potential surface impacts to observed intervals of persistent consecutive vortex anomalies, such as the consecutive strong anomalies throughout most of the 1990s and the consecutive weak anomalies in the early 2000s.

A lead-lag analysis of composite differences in the AMOC strength at three different latitudes is shown in (figure 3). The figure can be directly compared with figure $4 \mathrm{c}$ of Reichler et al. (2012) who suggest that decadal-scale variability in vortex strength acts to amplify a similar timescale of variability in the AMOC through resonance between the two signals. Similar to that work, an oscillatory AMOC response to the stratospheric anomalies is evident here, with significant positive anomalies in the AMOC at $45 \mathrm{~N}$ and $50 \mathrm{~N}$ at lags of approximately 3-5 years after persistent $\mathrm{NAM}_{10}$ intervals followed by negative anomalies at lags between 15 and 20 years. This response pattern is more clearly evident by taking the low pass filtered versions of the AMOC responses (figure $3 b, d$ and f). Even after the high-frequency signals have been removed, there are significant composite differences of up to $1.5 \mathrm{~Sv}$ at 15-20 year lags. (We note, however, that this low pass filtering of the AMOC time series reduces the overall variance so that the threshold for a composite difference to pass the significance test is lower, and this may increase the responses that are deemed significant shown in figure 3). 


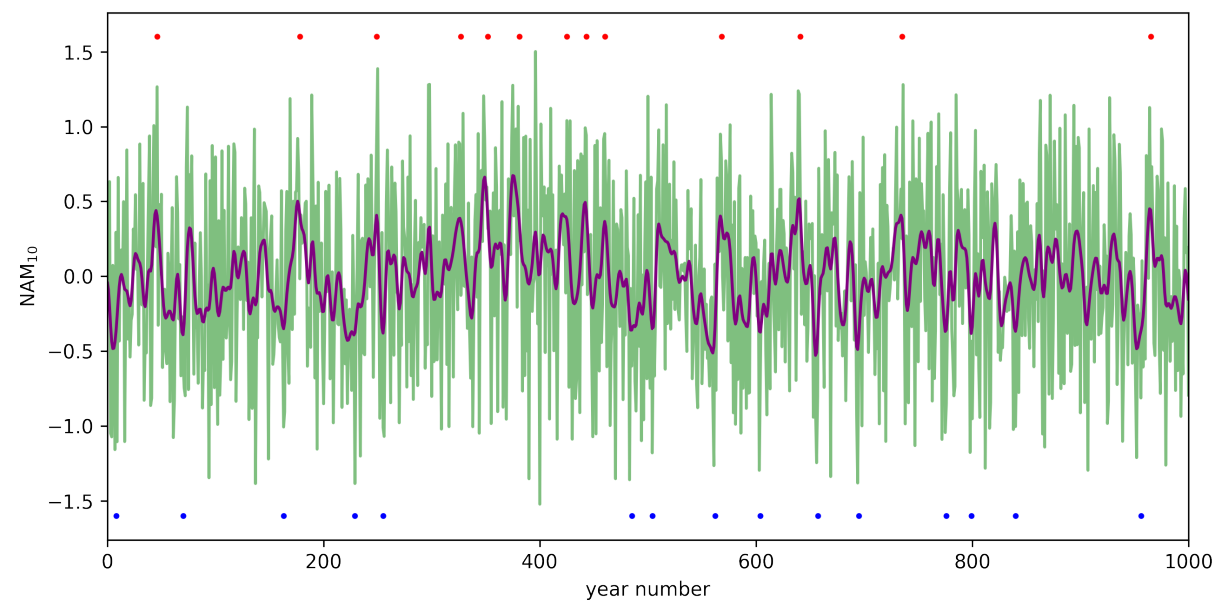

Figure 2. Time series of the December-March mean $\mathrm{NAM}_{10}$ index (green) level (green) and smoothed NAM 10 (purple) evaluated at the $10 \mathrm{hPa}$. The smoothed series is calculated by applying a Gaussian filter ( $\sigma=2$ years) to the green series. Red and blue dots indicate the occurrence of persistent strong and weak vortex intervals respectively defined as extreme values (top and bottom 5 percentiles) in the filtered $\mathrm{NAM}_{10}$ index. interval central years are selected such that at least 10 years lies between consecutive intervals.

Oscillatory response behaviour is not exhibited clearly by the AMOC at 30N, although negative anomalies at lags of 15-20 years after intervals are still visible. Response patterns at this latitude are also significantly smaller than those at $45 \mathrm{~N}$ and $50 \mathrm{~N}$ in the filtered composites (figure $3 \mathrm{a}$ and $\mathrm{b}$ ). One possible explanation of this is that the coupling mechanism between the $\mathrm{NAM}_{10}$ and $\mathrm{AMOC}$ may involve an AMOC response that originates at higher latitudes and then propagates equator-ward which leads to less forcing of the AMOC evaluated further south. Zhang (2010) also note latitudinal differences in the AMOC response so these differences between $30 \mathrm{~N}, 45 \mathrm{~N}$ and $50 \mathrm{~N}$ are not unexpected. The AMOC signals at $45 \mathrm{~N}$ and $50 \mathrm{~N}$ also exhibit significant positive anomalies preceding the persistent vortex intervals, at a lead of approximately 20 years and this is also present, albeit smaller in magnitude, in the low pass filtered indices. This precursor to persistent $\mathrm{NAM}_{10}$ intervals is not found in corresponding results from Reichler et al. (2012) and the role of this feature is considered in more detail in section 3.5.

We now examine this vortex-AMOC teleconnection in closer detail to explore possible physical pathways responsible for an AMOC response to persistent $\mathrm{NAM}_{10}$ intervals. Figure $4 \mathrm{~b}$ shows that there is also an oscillatory response in the NAO. This consists of a positive zero-lag response difference (consistent with figure 1), a significant negative NAO anomaly between lags of 10-18 years followed by a positive NAO response at lags of around 28 years but with smaller amplitude than the zero-lag response.

Also evident from figure $4 \mathrm{~b}$ is that the oscillatory responses of the NAO and AMOC are similar, with the NAO leading the AMOC response by 2-3 years. Both responses vary with periods of 28-30 years but, interestingly, the negative responses 

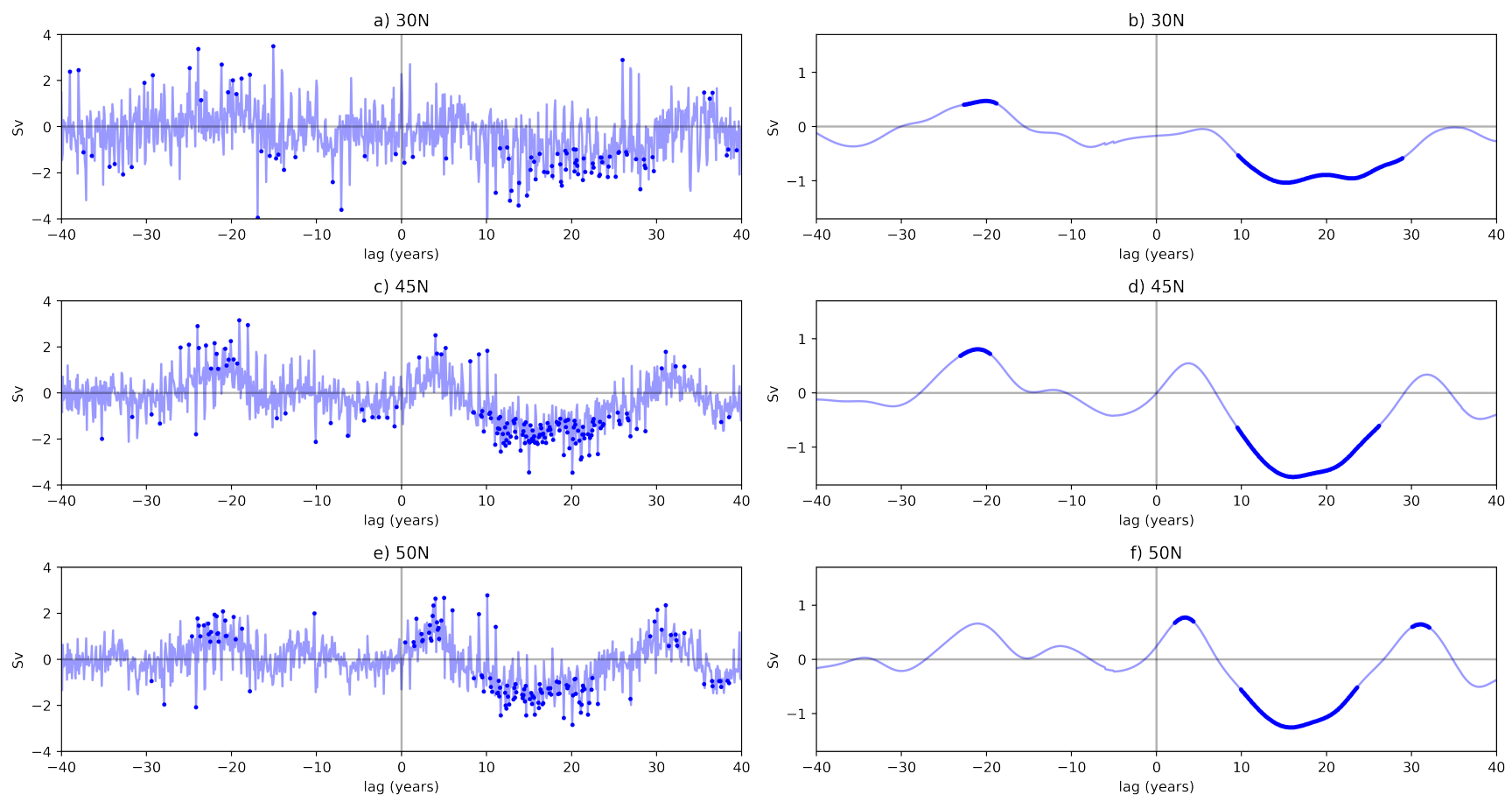

Figure 3. Lagged response of the AMOC index to persistent $\mathrm{NAM}_{10}$ intervals. Blue time series shows AMOC composite difference values between positive and negative $\mathrm{NAM}_{10}$ intervals defined in section 2.4. The $x$-axis denotes the lead (negative values) or lag (positive values) relative to the interval's central year. Black dots denote composite differences significant at the 95\% level under a 2-tailed student's t-test. Panels a, $\mathrm{c}$ and e show monthly AMOC composites while b,d and f show smoothed AMOC composites using a Gaussian filter ( $\sigma=2$ years).

in both signals are larger and longer-lasting at 10-20 year lags than those at zero and 28-30 year lags. This difference in the magnitude and persistence suggests that the NAO and AMOC response patterns cannot be explained as a straightforward oscillatory response to the $\mathrm{NAM}_{10}$ forcing at zero-lag. If this were the case then the response amplitude would be expected to decay with time and the negative response at 10-20 year lag would be smaller than the initial positive response. Instead, a form of feedback mechanism is required to explain the amplified 10-20 year lagged responses or a resonant mechanism as proposed in Reichler et al. (2012). If such a feedback mechanism were present then one might also expect to see some oscillatory behaviour in the smoothed $\mathrm{NAM}_{10}$ time series, in response to the feedback from the surface. To investigate this, figure 4a shows the corresponding lead-lag difference analysis for the $\mathrm{NAM}_{10}$ index (i.e. the smoothed $\mathrm{NAM}_{10}$ composited around its own extreme values). This supports the presence of a feedback mechanism since it also exhibits oscillatory behaviour with the same period of around 30 years. However, this oscillation is largely evident from the two positive peaks at zero-lag and $30 \mathrm{yr}-\mathrm{lag}$, with the latter being substantially damped. There is no significant response at lags of 10-20 years, where the NAO and AMOC responses were largest. This suggests that the negative NAO and AMOC responses at these lags are unlikely to be due to resonance with the $\mathrm{NAM}_{10}$ signal. 
Alternatively, a possible physical pathway could involve an amplifying feedback mechanism between the NAO and AMOC responses. In this scenario, the positive zero-lag NAO response would drive a positive ocean-atmosphere heat flux anomaly over the sub-polar North Atlantic as seen in the response patterns to individual vortex events in figure 1 . This heat flux anomaly would then lead to persistent negative anomalies in the near-surface ocean temperatures as heat is removed from the ocean via variations in wind stress and evaporation. The black line in figure 4 shows the lead-lag difference for ocean-atmosphere heat flux in the region encompassing the Subpolar North Atlantic $\left(45^{\circ}-65^{\circ} \mathrm{N}, 15^{\circ}-60^{\circ} \mathrm{W}\right)$. This region was selected to encompass the region with the largest heat flux response to individual vortex events in figure 1 (see middle row). Figure $4 \mathrm{c}$ the corresponding depth profile of ocean temperature response from the same region. A positive heat flux response, as well as an upper ocean (0-200m depth) cooling, is evident at 0-1yr lags. This heat flux perturbation would, in turn, drive a positive AMOC anomaly at 2-3 year lags via changes in the mixed layer depth and deep convection in the sub-polar North Atlantic, an effect discussed in Delworth et al. (1993) and Medhaug et al. (2012). This increase in AMOC strength would subsequently increase the Labrador Sea temperature via poleward transport of heat. This is confirmed by the positive, deep (down to 2000m) ocean temperature anomaly at a lag of 10-20 years in figure 4c. In turn, the reversal of the Labrador Sea temperatures can feedback onto the NAO (see e.g. Frankignoul et al. (2013), inducing a negative NAO phase at 10 years lags as the increased Labrador Sea heat content alters the ocean-atmosphere heat fluxes in the same region. Finally, this switch in the NAO phase would lead to a subsequent negative AMOC anomaly via the same heat flux mechanism outlined above for an opposite NAO phase. This sequence of feedbacks would thus act to enhance the persistence and magnitude of the secondary extreme in the NAO and AMOC. Reichler et al. (2012) also briefly suggest a similar mechanism to account for the AMOC response in their simulations, but involving a negative feedback of the AMOC onto itself as well as a role for the NAO.

\subsection{Response to strong and weak vortex intervals}

So far, we have considered composite difference responses to persistent strong and weak vortex intervals. However, we know that the vortex evolution during strong and weak vortex years is very different and this is likely to lead to differing interactions with surface and ocean variability. The surface responses to the two extremes are therefore unlikely to be equal and opposite. For example, weak vortex winters are mostly associated with SSWs whose impact at the surface is observed on average 0-60 days after their central date (Baldwin and Dunkerton, 2001). Furthermore, the vortex often exhibits a pre-conditioned state (see e.g. Charlton and Polvani (2007) and Bancalá et al. (2012)) in which it becomes anomalously strong in the weeks running up to an SSW. So the timing of SSW events within a given season will dictate both the overall strength of the NAM $_{10}$ measured over the winter season (which we use to construct the persistent NAM $_{10}$ index) and the overall strength of the subsequent surface response. In contrast, winters that exhibit an anomalously strong vortex will, on average, exhibit such behaviour throughout the whole season so the impact on the surface will be present for a larger fraction of the winter season.

To assess the influence from each type of vortex extreme separately, figure 5 shows the lead-lag composite analysis of the NAO, AMOC, NAM 10 and heat flux signals for the persistent positive (strong vortex) and persistent negative (weak vortex) $\mathrm{NAM}_{10}$ intervals separately. The AMOC patterns associated with each $\mathrm{NAM}_{10}$ type are slightly different. The persistently 

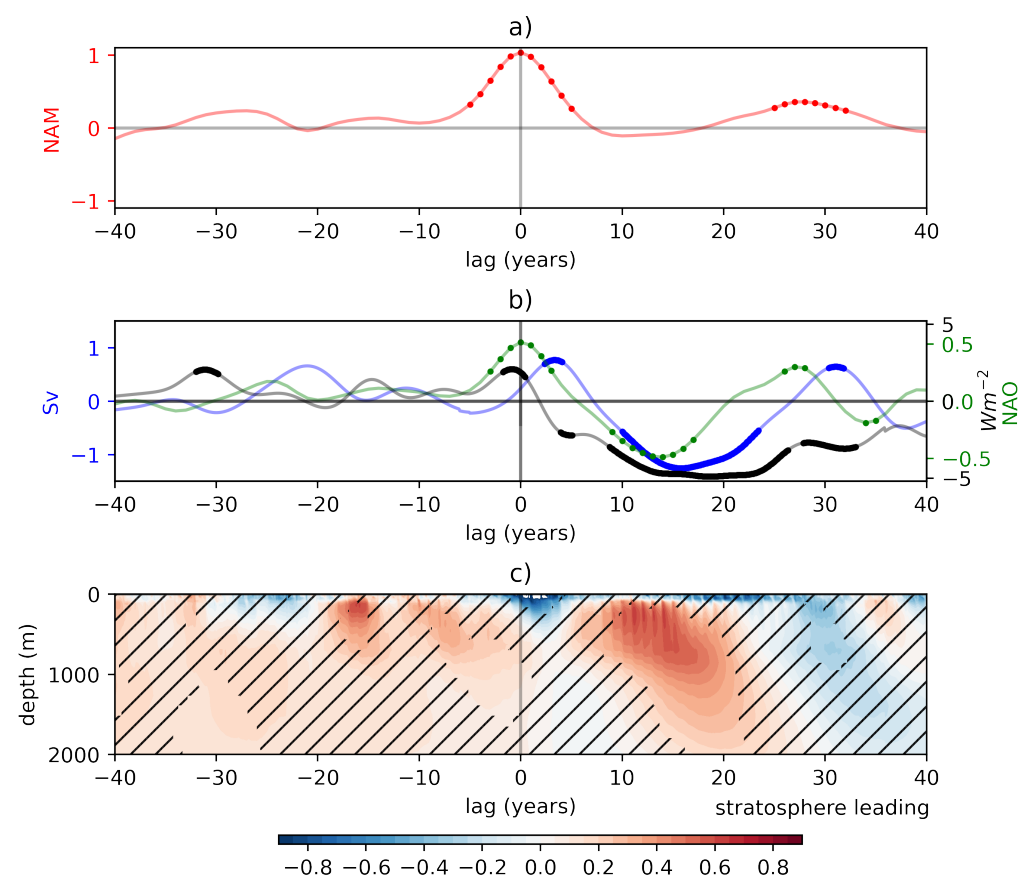

Figure 4. a: Composite differences of the smoothed $\mathrm{NAM}_{10}$ index around extreme $\mathrm{NAM}_{10}$ intervals (positive - negative intervals). b: Like figure $3 \mathrm{f}$ for the AMOC at 50N (blue), the Dec-Mar mean NAO index and the ocean-atmosphere heat flux (sum of latent and sensible fluxes) averaged over an Atlantic box defined by $45^{\circ}-65^{\circ} \mathrm{N}, 15^{\circ}-60^{\circ} \mathrm{W}$. All indices are smoothed with a Gaussian filter $(\sigma=2$ years $)$. c: lagged responses of ocean temperature anomaly depth profiles to persistent $\mathrm{NAM}_{10}$ intervals. Composite differences between strong and weak intervals are shown for the same Atlantic box as the heat flux index. Hatching indicates composite differences that are not significant at the 95\% level under a 2-tailed student's t-test.

strong vortex composite shows clear oscillatory behaviour with a period of approximately 28 years. These patterns resemble many of the features observed in the AMOC composite differences (figure 4d). Specifically, a positive AMOC anomaly is present at lags of 2-3 years, a negative AMOC anomaly at 15-20 years and a second positive anomaly at approximately 30 years. On the other hand, the persistently weak vortex composites exhibit a more complicated response, with double-peaked minima at lags of -20 and -11 years and double-peaked maxima at 14 and 25 years. The weak vortex composites also exhibit no significant AMOC response at 2-3 year lags, unlike the strong vortex composites. Both event types are associated with NAO anomalies at zero-lag but the response to strong vortex intervals is larger in magnitude, which is consistent with the larger 2-3 year lagged AMOC response to this event type. The 0-lag NAO response is followed by an extreme of the opposite sign at approximately 16yr and 14yr lags for strong and weak intervals respectively. As with the AMOC composites, the NAO response to persistently strong vortex intervals exhibits a pronounced oscillatory behaviour of periods around 28 years. The corresponding $\mathrm{NAM}_{10}$ analysis also shows oscillatory behaviour with periods of around 28 years. (We note that the $\mathrm{NAM}_{10}$ results show statistical significance at both lead and lag times. However, the lead/lag interpretation is less meaningful in this 
case since the $\mathrm{NAM}_{10}$ is used both as the signal and in the selection of the composites. The significance at both lead and lag times simply confirms that there is oscillatory behaviour). The double-peaked behaviour of the AMOC associated with weak intervals is also reflected somewhat in the sub-polar North Atlantic heat flux response (figure $5 \mathrm{c}$ ) with positive response peaks at approximately 11 and 20-year lags. There is also a 0-lag heat flux anomaly associated with weak vortex intervals corresponding to the negative NAO response but the corresponding response to strong intervals is not significant.

The asymmetry between the AMOC and NAO responses to persistently strong and persistently weak vortex intervals and the complexity of the separate responses show that the interactions between the $\mathrm{NAM}_{10}$ and these surface modes are complex, with some suggestion of oscillatory behaviour on different timescales. In the following sections, we address these complexities in more detail by analysing the frequency spectra of the time series and show that some of these complexities can be explained in terms of the non-stationarity of the signals.

\subsection{Non-Stationary Variability}

In an analysis of this same UKESM pi-control simulation, DM21 showed that variability of the stratospheric polar vortex occurs on a range of timescales and is highly non-stationary. Although the composite analysis presented above shows oscillatory behaviour with periods of approximately 30 -yr the results are likely complicated by the presence of non-stationary variability at other periodicities. We therefore analyse the frequency characteristics of the filtered $\mathrm{NAM}_{10}$ index. Figure 6 shows the wavelet power spectrum of this index. It reveals variability on a range of timescales. As expected from the composite analyses, the spectrum exhibits intermittent power throughout the whole simulation at periods between 15 and 40 years. There is also significant power corresponding to a period of approximately 90-100 years that persists for $\sim 300$ years of the simulation (year numbers 520-820; approximately 3 cycles) as well as power at the 50-year timescale that persists for 120 years (year numbers 500-620; approximately 2 cycles).

We note that much of the $\sim 30$-yr periodicity seen in the strong composite analysis is likely associated with significant wavelet power in the interval between years 300 and 410 because this interval displays the largest number of positive extremes in the smoothed $\mathrm{NAM}_{10}$ time series (compare the 30-yr wavelet power in figure 6 with the red dots in figure 1). The large number of elevated $\mathrm{NAM}_{10}$ extremes selected in this interval is also likely affected by the presence of extremely long timescales variability. Qualitative inspection of figure 2 shows that the underlying $\mathrm{NAM}_{10}$ amplitude increases from around year 200, reaches a peak at $\sim$ year 380 and thereafter declines. This means that years within this interval are more likely to reach the top 5 percentile and qualify as an anomalously strong vortex. The origin of this multi-centennial variability is unclear and robust analysis of such a low frequency signal is difficult as the wavelet power of this multi-century variability is located mostly outside the so-called "cone of influence" that marks the boundary at which edge effects become significant.

We also analyse the frequency characteristics of AMOC variability. Figure 7 shows the corresponding wavelet spectra of 

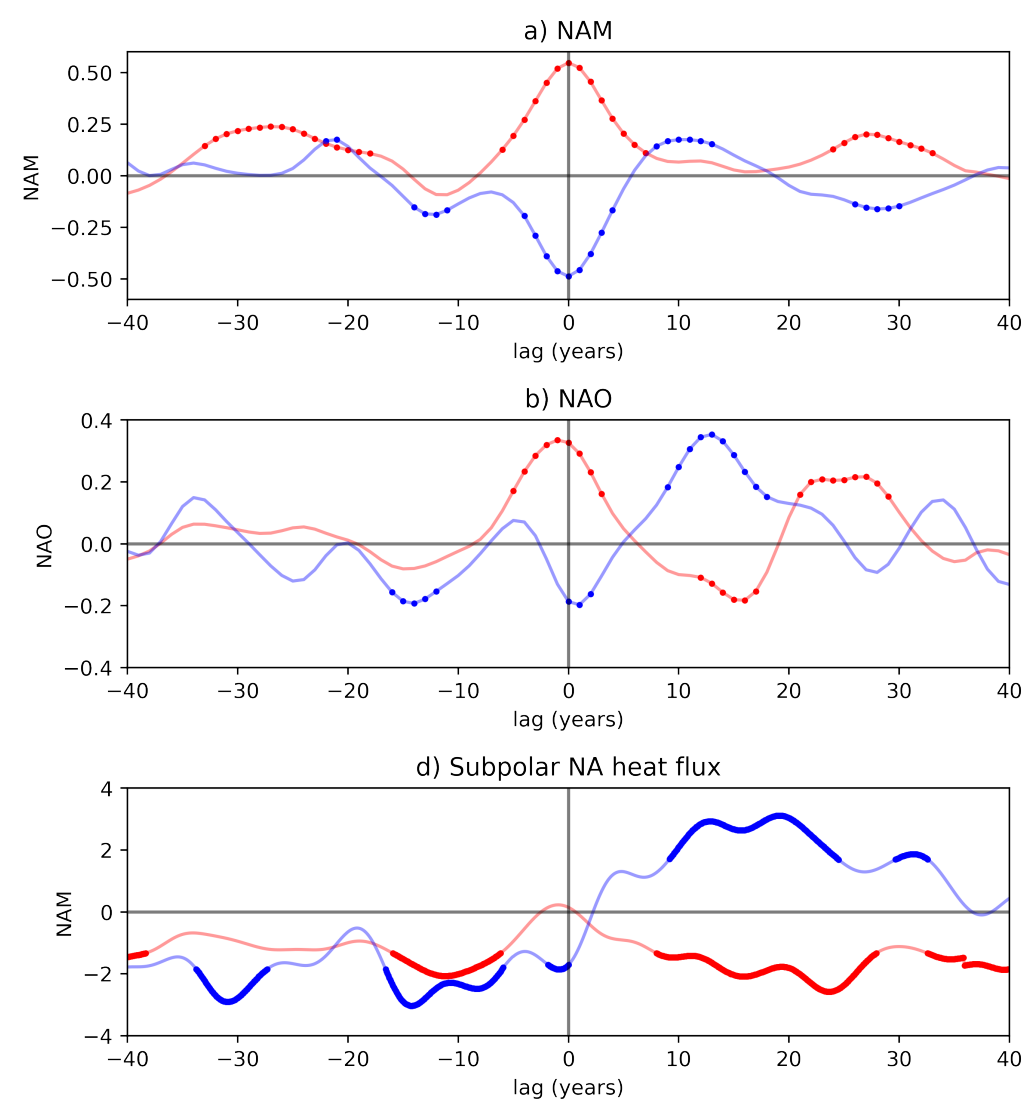

d) $\operatorname{AMOC}(50 N)$

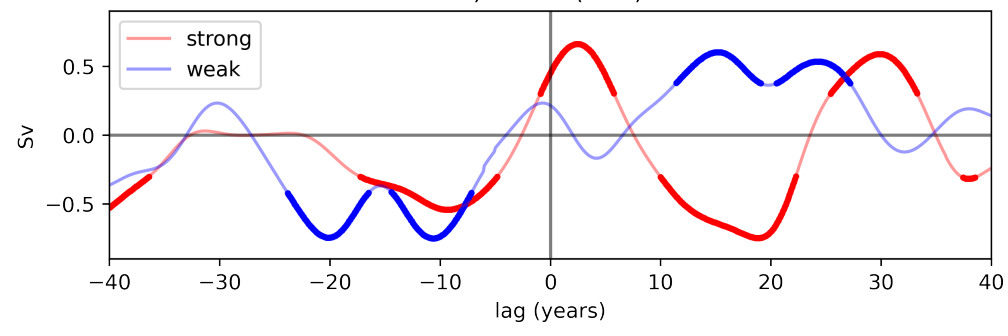

Figure 5. a: Composites of (a) Gaussian smoothed AMOC anomalies at 50N, (b) NAO, (c) NAM 10 and (d) subpolar NA heat flux associated with persistent vortex intervals of different types. On each sub-figure, the red (blue) plots show the lead/lag responses to composites of strong (weak) persistent $\mathrm{NAM}_{10}$ intervals. Solid dots denote composite anomalies are significant to the $95 \%$ level under a 2 tailed student's t-test.

measure of co-variability between the two indices at different periods. The wavelet spectrum for the AMOC at $50 \mathrm{~N}$ exhibits a peak in spectral power corresponding to approximately 130 years that persists for nearly 400 years of the simulation (and also at longer periods up to 250 years but boundary effects are an issue at these multi-centennial timescales, as discussed above). There are also portions of significant power at approximately 30-year and 50-year periods, both of which persist for 


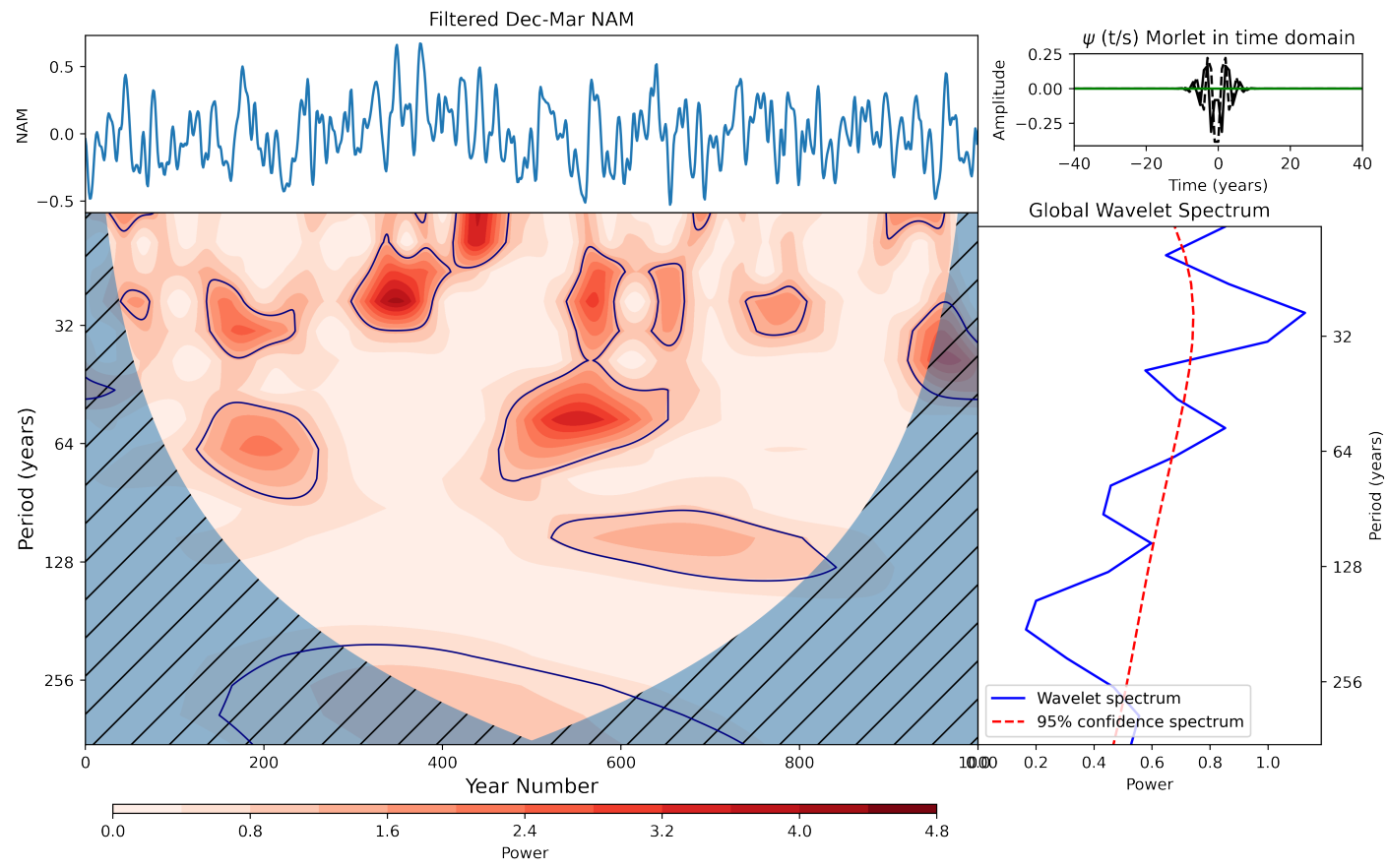

Figure 6. Top left: Dec-Mar NAM 10 values smoothed with a Gaussian filter ( $\sigma=2$ years). Bottom left: Wavelet power spectrum of time series in the top left sub-figure. Hatching represents areas outside the cone of influence in which edge effects are significant and power should not be considered. blue contours represent the 95\% confidence level assuming mean background AR1 red noise. Top Right: Morlet wavelet used for the wavelet transform in the time domain. Bottom right: Global power spectrum, the wavelet power averaged over the whole simulation (blue line), and global 95\% confidence spectrum (red dashed line).

approximately 2 cycles ( $\sim 60$ years and $\sim 100$ years respectively) which are also apparent in the global power spectrum. We also note that the main 30-yr power comes from the 300-400 year interval, coinciding with the interval of most activity in both the $\mathrm{NAM}_{10}$ analysis (figure 6) and the selected high $\mathrm{NAM}_{10}$ percentiles (figure 1).

The cross power spectrum between the filtered $\mathrm{NAM}_{10}$ and the AMOC shows 3 distinct features corresponding broadly to the three timescales prominent in the individual spectra of both indices. Significant cross power is evident at 90-100 year periods for approximately 350 years (between 450 and 800 years; 3-4 cycles). The phase relationship between the signals (indicated by arrows on figure 7) within this portion of the cross spectrum show a mixture of left-pointing arrows in the earlier portion, which indicate an anti-correlated relationship ( $\pi$ out of phase) and downward pointing arrows in the later portion that indicate a $\frac{\pi}{2}$ phase relationship. This later phase relationship can be interpreted in a number ways, with maxima in the AMOC leading to maxima in the $\mathrm{NAM}_{10}$, minima in the $\mathrm{NAM}_{10}$ leading to maxima in the AMOC or maxima in the NAM 10 index coinciding with maxima in the rate of change of the AMOC (see section 2.2 for more details of the cross spectra arrows and how they are derived). There is also significant cross-spectral power centred around 30 years (between 300-400 years; 3 cycles) 
and 50 years (between 500-600 years; 2 cycles). In contrast to the 90-yr periodicity, the phase arrows point to the right and slightly upwards, indicating that maxima in the $\mathrm{NAM}_{10}$ index lead maxima in the AMOC by a small fraction of the cycle. This phase relationship is consistent with the composite analysis presented in figures 3 and 5 that indicated that a positive (negative) $\mathrm{NAM}_{10}$ leads to a positive (negative) AMOC response approximately 2-3 years later. The wavelet spectra for the AMOC at $30 \mathrm{~N}$ and $45 \mathrm{~N}$ are provided in figures A1a and A2a. They show broadly the same features as that of the AMOC at $50 \mathrm{~N}$ however it is notable that the AMOC at $30 \mathrm{~N}$ does not exhibit significant variability on the 50 and 30 -year timescales. This is reflected in the cross spectrum with the smoothed $\mathrm{NAM}_{10}$ index which shows minimal cross power on these timescales (figure A1b).

To understand these non-stationary signals in the context of the proposed mechanism for vortex-AMOC interactions involving the NAO, we also analyse the power spectrum for the Dec-Mar NAO (figure 8). The wavelet power spectrum for the NAO (figure 8a) exhibits a portion of significant power at periods of 30 years between $\sim 300-400$ years as well as a feature at 50 years between $\sim 500-600$ years similar to the $\mathrm{NAM}_{10}$ and the AMOC. Furthermore, the cross power spectrum between the $\mathrm{NAO}$ and the $\mathrm{NAM}_{10}$ indicate that signals in the two indices on the $\sim 30$ and $\sim 50$ year periods are also coincident in time for the 70-100 years they persist for. The phase relationship between these signals is small (arrows pointing to the right) indicating an in-phase relationship between the indices, which is consistent with the zero-lag relationship between the NAO and filtered $\mathrm{NAM}_{10}$ extremes presented in the composite analysis (figures 4 and 5). The NAO wavelet analysis shows no significant power on the 90-100 year timescale. This suggests that the co-variability between the $\mathrm{NAM}_{10}$ and AMOC on these longer timescales does not involve the NAO and is likely to arise through different mechanisms. We return to examine this feature in more detail in section 3.5.

Results from this wavelet analysis may also explain the different behaviour of the AMOC around persistent positive and negative $\mathrm{NAM}_{10}$ intervals (figure 5). Firstly, we note that the contribution to the composites from the prime interval exhibiting $\sim 30$-year oscillatory behaviour ( 300-400 years) comes solely from a collection of persistent strong $\mathrm{NAM}_{10}$ intervals (see the red dots on figure 2). In contrast, a high proportion of the weak $\mathrm{NAM}_{10}$ contributions to the composite analysis (8 out of 13) occur within the interval between $\sim 500-600$ years which exhibits variability at both 50yr and 90yr periodicity. The complicated double-peaked behaviour of the AMOC response following persistent weak vortex intervals can now be better understood: The double minima in AMOC response at $10 \mathrm{yr}$ and $20 \mathrm{yr}$ leads and at $15 \mathrm{yr}$ and $25 \mathrm{yr}$ lags can now be explained as manifestations of the 50-yr and 90-yr AMOC responses e.g. a half-cycle between the minimum at 10yr lead and maximum at $15 \mathrm{yr}$ lag (a half-cycle of 25 years) gives a periodicity of 50yrs, while a half-cycle between the minimum at $20 \mathrm{yr}$ lead and $25 \mathrm{yr}$ lag (thus a half-cycle of 45yrs) give a periodicity of 90yrs. Additional support for this interpretation comes from the fact that the NAO composite analysis (figure 5b) shows a response that corresponds broadly with the AMOC minimum at 10yr lead and maximum at $15 \mathrm{yr}$ lag, suggesting a mechanism that involves the NAO on the 50-yr timescale but there is no corresponding response in the NAO at the 90-yr periodicity, in agreement with the wavelet spectra and cross spectra in figure 8 which indicates that the NAO does not exhibit variability on timescales of $\sim 90$ years. 


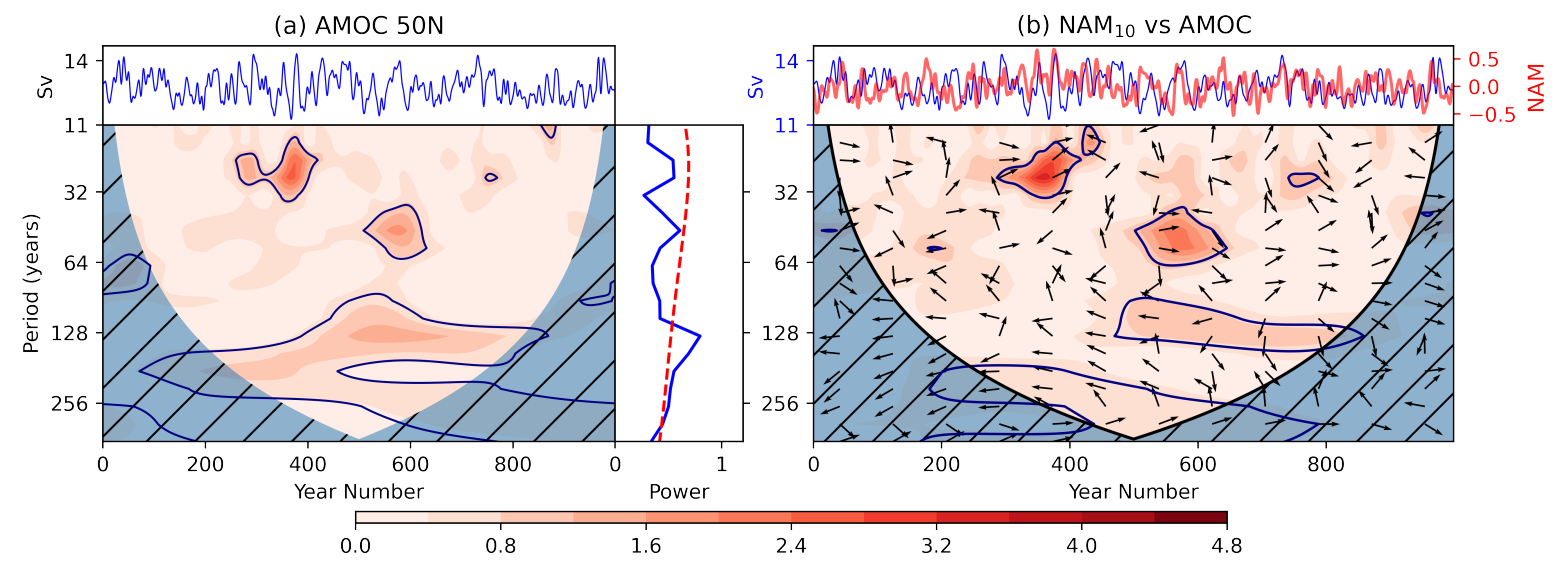

Figure 7. (a, top): AMOC time series at 50N, a, bottom left: Wavelet power spectrum (shaded contours represent wavelet power and yellow contours the $95 \%$ significance level compared to an AR1 process), a, bottom right: global wavelet power spectrum (blue) and $95 \%$ confidence level (dashed red). b: Cross spectra between Filtered Dec-Mar NAM 10 series and the AMOC index. b, top: NAM 10 and AMOC time series. b, bottom: Cross power spectrum. Shading indicates cross power, yellow contours the $95 \%$ confidence interval and arrows the relative phase angle between signals in the time series (to the right: in phase, vertically upwards: $\frac{\pi}{2}$ out of phase with positive peaks in the $\mathrm{NAM}_{10}$ leading those in the AMOC, to the left: $\pi$ out of phase, vertically downwards: $\frac{\pi}{2}$ out of phase with positive peaks in the AMOC leading those in the NAM).

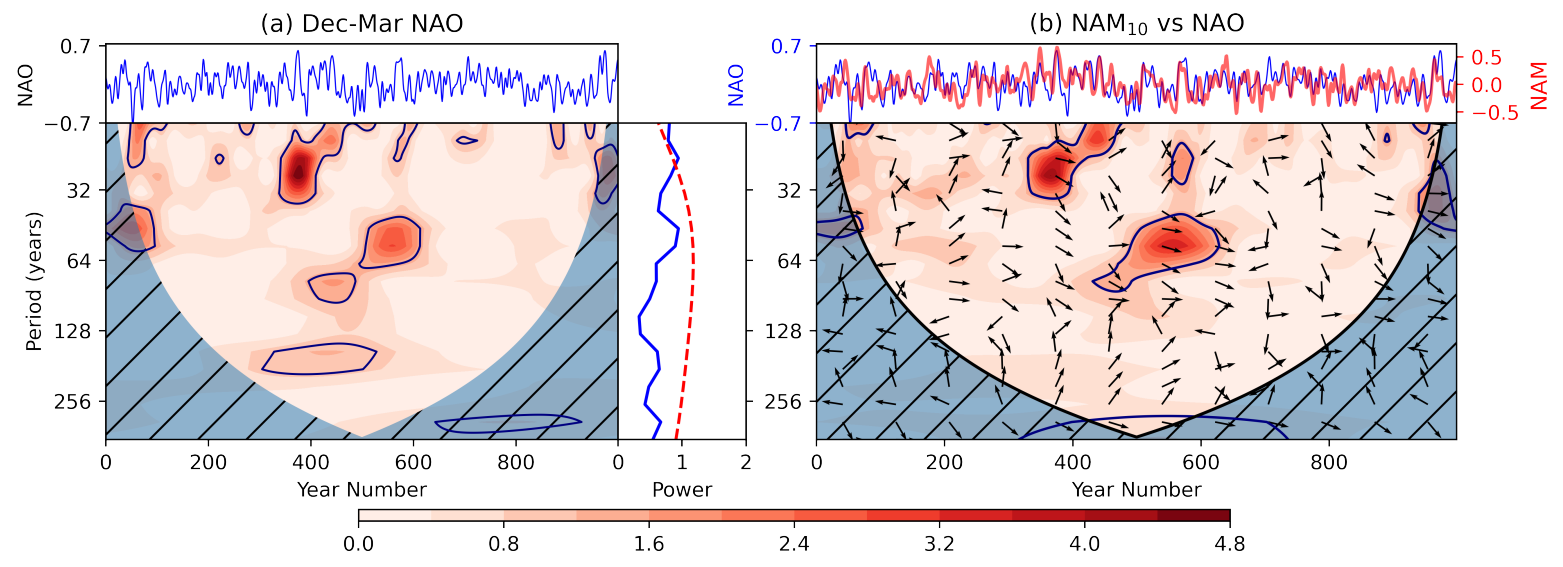

Figure 8. like figure 7 for the Dec-Mar NAO index. (a) shows the wavelet power spectrum of the NAO and (b) the cross power spectrum between the NAO and the $\mathrm{NAM}_{10}$ index. 


\subsection{Surface Forcing of the Stratosphere}

The absence of an NAO signal that corresponds to the $90 \mathrm{yr}$ periodicities seen in both the $\mathrm{NAM}_{10}$ and $\mathrm{AMOC}$ wavelet spectra and in the AMOC-NAM cross spectrum (figure 7) indicates that the mechanism for the stratosphere - AMOC teleconnection on this longer timescale may be distinct in nature to those observed at the 30 and 50-year periodicities. As noted earlier, the phase relationship associated with this feature is also different to the shorter timescales ( $\frac{\pi}{2}$ out of phase) suggesting that the direction of causality is also switched i.e. that the AMOC leads the stratosphere response on these timescales rather than vice versa. To study this more closely we investigate possible pathways involving variability on this timescale.

In an earlier analysis of this UKESM pi-control simulation DM21 highlighted the $\sim 90 \mathrm{yr}$ variability in the frequency of SSWs and demonstrated that this was closely associated with similar timescale variations in the amplitude of the QBO (and in particular, the westerly QBO phase). Figure 9a shows the wavelet spectrum of the same QBO index employed by DM21 after smoothing with the same Gaussian filter utilised throughout this work (see DM21 figure 12 and also section 2 for a description of how the QBO index was derived). A portion of significant power at $\sim 90$-year periods persists for approximately 200 years of the simulation between years 600-800, which coincides with the significant response in the same interval of the NAM 10 and AMOC spectra at 90yr periodicity. Cross spectra of the QBO index with the smoothed $\mathrm{NAM}_{10}$ index (figure $9 \mathrm{~b}$ ) also corroborates the findings of DM21, with coincident signals at the 90-year timescales and right-pointing arrows that indicate an in-phase relationship, so that an interval of persistently strong positive (westerly) QBO anomalies coincides with an interval of persistent positive (strong) polar vortex anomaly. The sign of this teleconnection is consistent with the well-known Holton-Tan teleconnection (Lu et al., 2008, 2014) but it is present on much longer timescales. DM21 showed that this long-term variability originates primarily from long-term variations in the strength of the westerly QBO phase.

While the long-timescale QBO-vortex teleconnection was demonstrated by DM21 (and confirmed here), the cause of the long-term westerly QBO variability was not established. In a preliminary investigation, DM21 performed a wavelet analysis of equatorial SSTs in various regions, including the equatorial East Pacific, to explore whether the $\sim 90$-yr QBO variability could be explained by SST triggering of convective activity that generates the gravity and other equatorial waves that contribute to the QBO. However, no 90-year periodicity in equatorial SSTs was found. DM21 also performed a corresponding analysis of an index representing the strength of the Aleutian Low, to explore whether that could explain the 90-yr signals in both the QBO and the polar vortex via a modulation of the strength of large-scale planetary wave forcing, but no periodicity at 90 years was found in the AL index. Nevertheless, the extremely long period of the QBO and vortex variations suggests a driving mechanism that is likely linked to the ocean, because of the characteristic long oceanic timescales. We therefore extend the investigation of DM21, to pin down the mechanism that links the observed variability on 90-yr timescales in the AMOC, the QBO and the polar vortex.

To extend this investigation we examine the variability of the East Pacific top-of-atmosphere outgoing longwave radiation (OLR) as a proxy for deep convection (instead of using the East Pacific SSTs, as in DM21). When deep convection is enhanced, cloud top height is increased and therefore OLR is reduced. Figure 9c shows the wavelet analysis of the Sep-Nov OLR in the East Pacific. It exhibits 90-year periodicity, as well as significant cross power with the smoothed QBO amplitude and the 
$530 \mathrm{NAM}_{10}$ index (figures 9d,e). The signals in the OLR and both the QBO and NAM 10 are anti-correlated (left-pointing arrows indicating a $\pi$ phase difference). This is consistent with reduced OLR (increased deep convection) leading to greater QBO amplitude through increased wave forcing. The corresponding cross spectra between the AMOC and the OLR metric (figure 9f) also indicates a significant portion of cross power in the interval $\sim 600-800$ years co-located with the feature seen in the $\mathrm{NAM}_{10}$ spectrum (see the dashed contours in figure 9 which indicate the region with significant power in the $\mathrm{NAM}_{10}$ spectrum). The phase relationship, in this case, is mostly $\frac{\pi}{2}$ (the majority of arrows pointing upwards) indicating that one of the quantities depends on the time rate of change of the other. This result is similar to the study of Timmermann et al. (2005) who found a sensitivity of the equatorial Pacific region to periodic forcing of the AMOC. Their study showed a dependence of the Pacific thermocline on the rate of change of the AMOC. (We note, however, that the 7.5 Sv AMOC perturbation imposed in their study was considerably larger than the AMOC variations in our simulation). Similarly, a lagged, cross-basin 540 connection between the NA overturning circulation and Pacific Sea Surface Height (SSH) was proposed by Cessi et al. (2004) who interpreted it in terms of the propagation of oceanic Kelvin and Rossby waves with anomalies communicated between Atlantic and Pacific via the Indian Ocean as well as through the Drake Passage. We therefore suggest this as a possible pathway for the influence of the AMOC on the polar vortex at 90-yr timescales in this simulation, via modulation of deep convection in the East Pacific that influences the amplitude of the QBO. A more detailed examination of the intermediate steps in this proposed physical pathway is required to confirm this, but this is outside the scope of the study. 

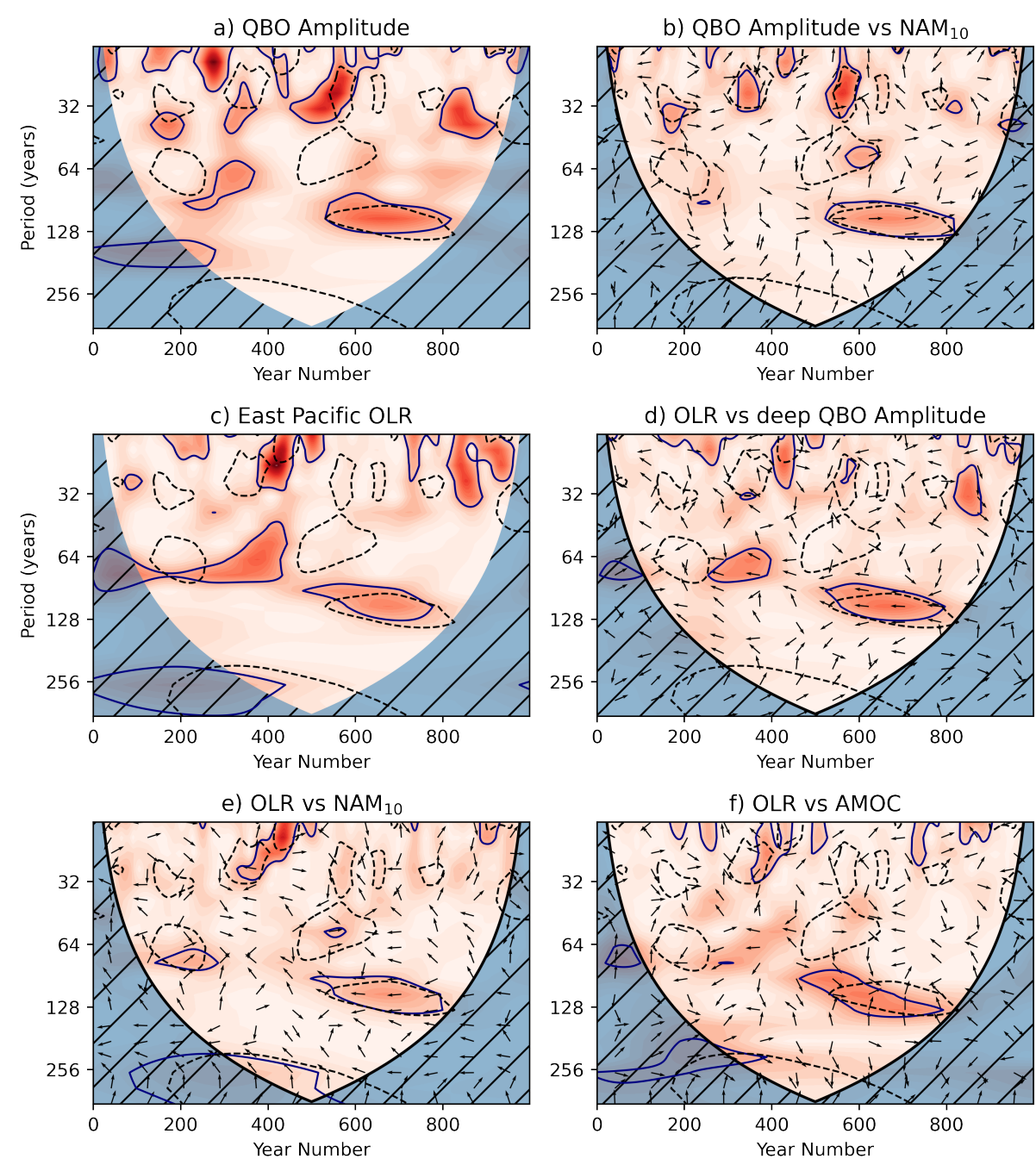

Figure 9. (a): Wavelet power spectrum for the Sep-Nov deep QBO amplitude (see section 2.4). (b) cross power spectra between deep QBO Amplitude (Sep-Nov) and smoothed NAM $_{10}$ (Dec-Mar). (c): Wavelet power spectrum for the Sep-Nov Area weighted average equatorial East Pacific OLR (see section 2.4). d-f: cross power spectra between combinations of East Pacific OLR, deep QBO Amplitude (both SepNov means), AMOC at 50N (annual mean, all months) and $\mathrm{NAM}_{10}$ (Dec-Mar) indices all smoothed with the same Gaussian filter as is used throughout $(\sigma=2$ years $)$. Indices involved are indicated by the sub-figure titles. Shading indicates the cross power, using the same colour scale as in figures 6-8. Solid contours indicate the 95\% confidence interval for the power spectrum and dashed contours show the $95 \%$ confidence interval for the $\mathrm{NAM}_{10}$ spectrum, for ease of comparison. Arrows indicate the relative phase angle between the signals in the indices. 


\subsection{Contribution of the stratosphere to recent AMOC changes}

Our analysis of the UKESM simulation has identified co-variability between modes of variability in stratospheric circulation and the AMOC. Intervals in which the winter stratospheric polar vortex is consistently strong are, on average, followed by an extended negative anomaly in AMOC strength with a lag of approximately 15-20 years (figure 3f). Recent observations of the AMOC have shown a negative trend in circulation strength of approximately $-2.7 S v$ between 2004 and 2012 (Smeed et al., 2018) before a marginal recovery after 2012 (Smeed et al., 2019). Modelling studies have proposed a key role for anthropogenic forcing in AMOC slowdown over the 20th century and into the future (Liu et al., 2017; Bakker et al., 2016; Liu et al., 2019). However, the drivers of observed AMOC trends in the 21st century are not well understood. The results shown in the previous sections suggest the possibility that stratospheric variability has also contributed to the observed AMOC changes, in response to nearly a decade of strong vortex years in the 1990s followed by a sequence of years with a weak, disturbed vortex in the early 2000s.

Using the relationship seen in the model between the modelled NAM, NAO and AMOC we can now compare the observed NAM, AMOC and NAO indices for the interval 1979-2020 from the ERA5 and RAPID array datasets and assess the potential contribution of stratospheric variability to the observed AMOC trend (figure 10). The $\mathrm{NAM}_{10}$ index (red bars) is characterised by an interval of strong vortex winters between 1988 and 1997 in which all but 2 winters exhibited a positive NAM 10 . This interval also contains no SSWs (Pawson and Naujokat, 1999). This is followed by a run of winters between 1998 and 2005 which exhibit anomalously weak $\mathrm{NAM}_{10}$ values with SSWs almost every year Manney et al. (2005). The filtered NAM 10 index (red dashed line) reflects the presence of these time intervals with a peak in positive values centred around 1995 followed by a negative extreme centred around 2003. The smoothed NAO (green dashed line) from the same dataset reflects some of these variations in the $\mathrm{NAM}_{10}$ with positive NAO extremes in the 1990s. The long-term envelope of the NAO does not remain positive for as long as the NAM, primarily due to the anomalous negative NAO in 1996 (Halpert and Bell, 1997). The presence of this anomalous negative NAO in 1996 and the absence of a clear NAO anomaly in the following year despite the presence of strong positive anomalies in the stratospheric $\mathrm{NAM}_{10}$ is indicative of the range of other factors that influence the NAO in addition to the vortex. The AMOC strength estimated from the Rapid Array observations between 2005 and 2019 is also shown (blue curve) and shows a negative trend between 2005 and 2012 followed by a recovery from 2012 onwards (Smeed et al., 2018, 2019).

The interval of observed consecutive strong NAM winters in the 1990s is anomalous in the reanalysis period although the available data record is rather short to allow a robust assessment. The amplitude and longevity of the observed anomaly are also large when compared to the UKESM simulation. Only 2 intervals in the UKESM simulation exhibit at least as many consecutive winters with strong (high $\mathrm{NAM}_{10}$ ) conditions. These 2 intervals occur in the 300-400 year interval (centred around years 349 and 376) as shown in figure 11a. They each exhibit a sequence of 10 consecutive Dec-Mar anomalously positive NAM 10 values. The 2nd interval exhibits 14 strong or marginally weak consecutive winters with the allowance for the small negative NAM $_{10}$ value at year number 379. The presence of these two intervals is reflected in the smoothed $\mathrm{NAM}_{10}$ values (figure $11 \mathrm{~b}$ ) and they 


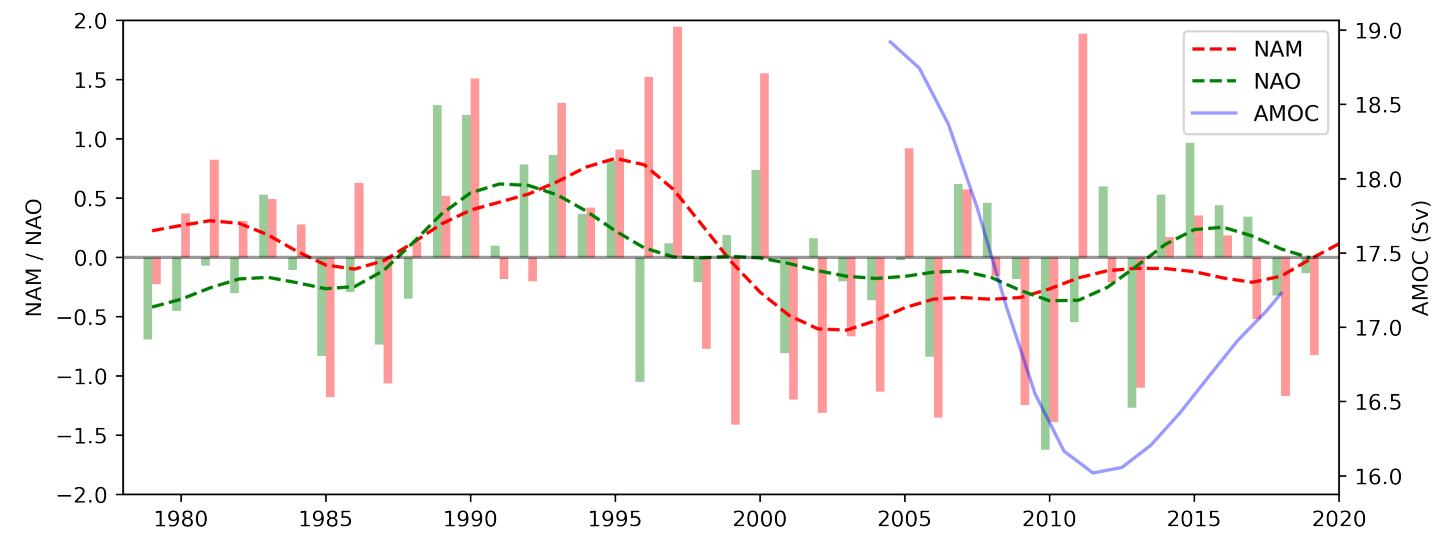

Figure 10. Time series of the Dec-Mar NAO index (green bars), NAM 10 index (red bars) from the ERA5 dataset. Dashed lines correspond to indices shown by bars smoothed with a Gaussian filter ( $\sigma=2$ years). Also included is the annual AMOC time series at $26 \mathrm{~N}$ from the rapid array dataset (blue).

represent the two of the three largest values of the filtered $\mathrm{NAM}_{10}$ index (0.66 and 0.67). The corresponding smoothed AMOC index during these 2 intervals (blue curve in figure 11a) shows a positive AMOC response at lags of 2-3 years followed by a negative response at 17-20 years, in good agreement with figure 3f. The negative responses at 17-20 years following these 2 intervals of strong $\mathrm{NAM}_{10}$ years are the 1st and 3rd greatest in magnitude compared to all other responses to persistent strong intervals. This is confirmed by figure 11c which shows the lagged AMOC response following all of the identified intervals with persistent positive $\mathrm{NAM}_{10}$ anomalies (the two identified around 349 and 376 years are shown in black).

To estimate the response amplitude of the AMOC to an interval of persistently strong vortex winters, figure 11d shows a scatter plot of the central NAM 10 index of these intervals against the AMOC anomaly at $50 \mathrm{~N}$ lagged by 17 years. This reveals a strong linear relationship $(r=-0.908)$ between the size of the persistent vortex anomaly and the subsequent negative anomaly in the AMOC at 50N 17 years later. The PDF of surrogate correlations used to assess the statistical significance (following the method outlined in section 2) is displayed in figure A3a along with the correlation generated by the observed NAM $_{10}$ data. It shows that the $r$ value lies well outside the distribution of surrogate correlations, indicating the high level of significance of the linear relationship.

A linear regression analysis on this data yields an estimated relationship between the variables which satisfies

where $A M O C_{+17}^{\prime}$ is the 17 year lagged AMOC anomaly at $50 \mathrm{~N}$ and $N A M \max$ is the magnitude of the positive extreme in smoothed $\mathrm{NAM}_{10}$ at the centre of each interval. We can then use this relationship to predict the AMOC response to the observed sequence of strong vortex years in the 1990s. The maximum smoothed NAM 10 occurs in 1996 so, using this relationship, the 
maximum AMOC response associated with the stratosphere would be expected 17 years later (2013) with an amplitude of
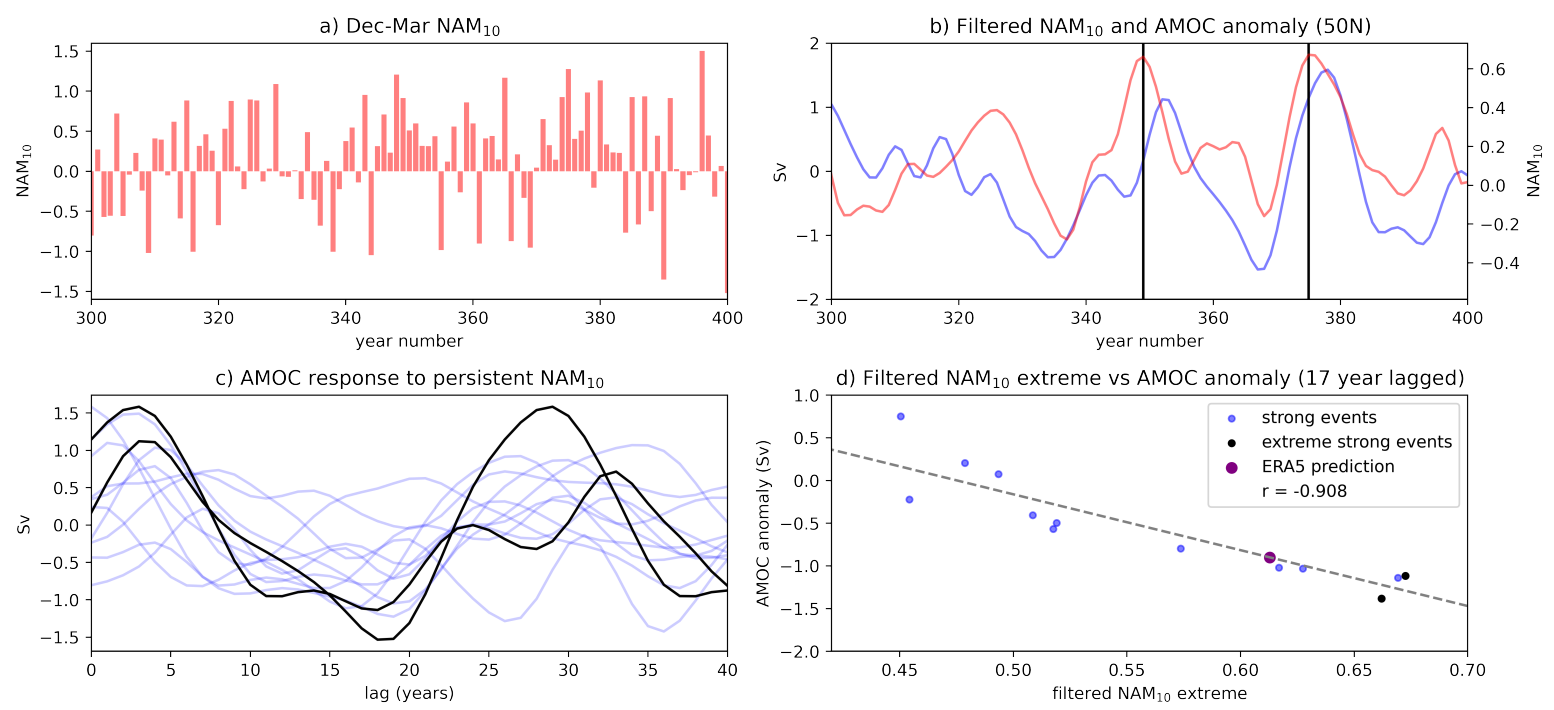

Figure 11. a: Dec-Mar NAM 10 index (red bars) from the UKESM simulation between year numbers 300 and 400 . b: AMOC (blue) and $\mathrm{NAM}_{10}$ (red) indices smoothed with the Gaussian filter ( $\sigma=2$ years) between year numbers 300 and 400 of the UKESM simulation. Black vertical lines show the location of the largest smoothed $\mathrm{NAM}_{10} \mathbf{c}$ : AMOC response to persistent strong NAM 10 intervals. Light blue lines denote lagged AMOC responses of the AMOC from the whole UKESM simulation, black lines show AMOC responses to NAM 10 intervals marked in b by vertical black lines. $\mathbf{d}$ : Scatter plot of filtered $\mathrm{NAM}_{10}$ index values occurring at persistent strong NAM $\mathrm{N}_{10}$ intervals throughout the whole UKESM simulation ( $y$-axis) against AMOC anomalies at 50N lagged 17 years after persistent intervals' central year ( $x$-axis). Blue points indicate persistent intervals and black dots represent the 2 intervals displayed in $b$. The dotted line represents the linear line of best fit for the points in black and blue. Also included is the 17-year lag AMOC anomaly predicted by projecting the regression coefficients used to construct the linear fit onto the maximum smoothed $\mathrm{NAM}_{10}$ index in the ERA5 dataset (purple point).

This prediction suggests that approximately 30\% of the observed reduction in AMOC strength between 2005 and 2013 (0.89 $\mathrm{Sv}$ compared with $2.9 \mathrm{~Sv}$ in total) could be due to the response of the ocean to persistent forcing from consecutive strong vortex winters that occurred during the 1990s. We note, however, that our derivation of the modelled vortex-AMOC relationship is based on the AMOC response at 50N, where the response amplitude is largest, whereas the Rapid Array dataset provides a measurement of AMOC strength at $26 \mathrm{~N}$. Figure 12 shows the scatter plot of filtered $\mathrm{NAM}_{10}$ extreme magnitudes and lagged AMOC responses from the model at 30N. At this latitude, the linear relationship is significantly weaker than at 50N $(r=0.652$ for $30 \mathrm{~N}$ vs $r=0.908$ for $50 \mathrm{~N}$ ) but the correlation coefficient remains significant at the $95 \%$ level. The predicted contribution from the strong vortex interval in the 1990 s to the AMOC strength at $30 \mathrm{~N}$ is reduced to $-0.49 S v$, (figure 12 , purple dot) 
suggesting that approximately $17 \%$ of the negative trend in the RAPID AMOC data may be due to stratospheric forcing from the 1990s. This is consistent with the composite analysis in figures in 3a and b which indicate that the modulation of the AMOC by the smoothed $\mathrm{NAM}_{10}$ is less pronounced at $30 \mathrm{~N}$ than at higher latitudes.

A similar analysis of the relationship between the magnitude of smoothed negative (weak) $\mathrm{NAM}_{10}$ extremes and the lagged AMOC response (not shown) yields a much weaker relationship $(r=-0.21)$ that is not statistically significant. This asymmetry

615 in the vortex-AMOC relationship between extreme positive and negative NAMs is perhaps not surprising, given that the surface impact of SSWs (that give rise to the negative NAM events) depends on the timing of the SSW within the winter season whereas strong positive NAM intervals exhibit strong vortex conditions throughout the winter.

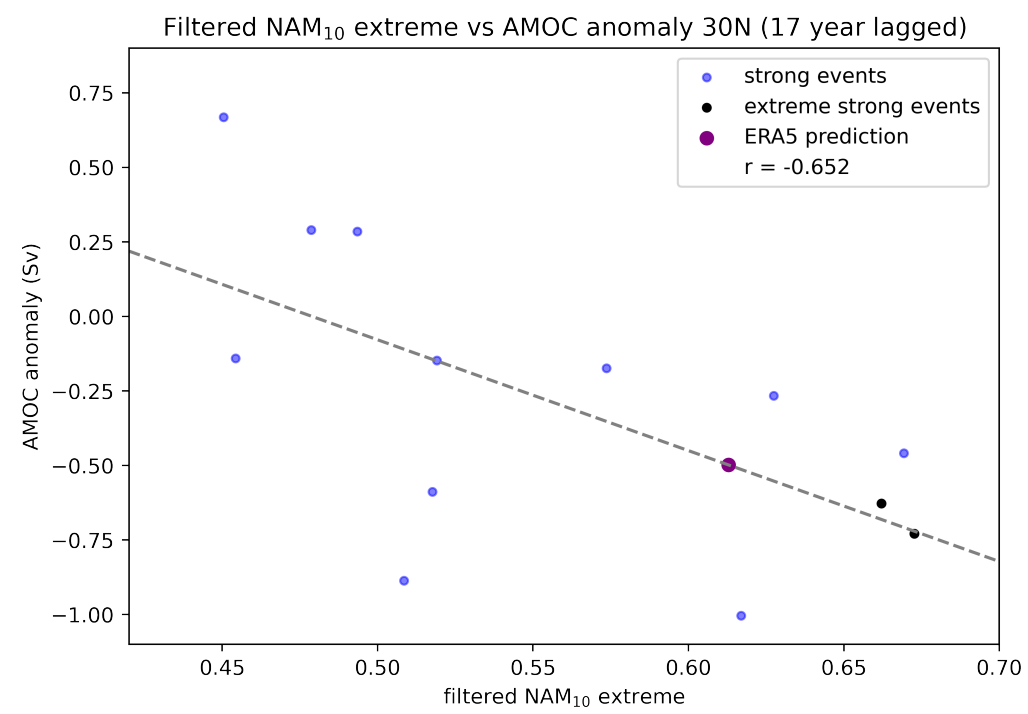

Figure 12. Like figure 11d for AMOC responses at 30N: Scatter plot of filtered $\mathrm{NAM}_{10}$ index values occurring at persistent strong $\mathrm{NAM}_{10}$ intervals throughout the whole UKESM simulation ( $y$-axis) against AMOC anomalies at 30N lagged 17 years after persistent intervals' central year ( $x$-axis). Blue points indicate persistent intervals and black dots represent the 2 intervals displayed in $b$. The dotted line represents the linear line of best fit for the points in black and blue. Also included is the 17-year lag AMOC anomaly predicted by projecting the regression coefficients used to construct the linear fit onto the maximum smoothed $\mathrm{NAM}_{10}$ index in the ERA5 dataset (purple point).

\section{Summary and Conclusion}

In this study we have analysed the influence of persistent polar vortex extremes on surface and ocean circulation in a 1000year pi-control simulation of UKESM1. Persistent vortex anomalies are identified using a smoothed $\mathrm{NAM}_{10}$ index which characterises intervals of approximately 6-8 years during which the $\mathrm{NH}$ winter vortex is anomalously strong (positive $\mathrm{NAM}_{10}$ 
anomaly) or weak (negative $\mathrm{NAM}_{10}$ anomaly). While the surface impacts of stratospheric extremes in individual winters has received much attention (Baldwin and Dunkerton, 2001; Domeisen, 2019; Charlton-Perez et al., 2018), the surface impacts of consecutive sets of persistently anomalous winters have been less well studied and teleconnections between the stratospheric vortex and ocean variability are not well characterised or understood.

We examine the AMOC response to long-term variations in the stratospheric polar vortex using composite analysis of the AMOC strength following persistent anomalous NAM 10 intervals. We find oscillatory responses in the NAO and the AMOC consistent with previous work (Reichler et al., 2012). Diagnosis of the model supports a mechanism in which a persistently strong vortex (positive NAM) perturbs a positive NAO anomaly which subsequently induces a positive AMOC response at 2-3 year lags via an increase in subpolar North Atlantic ocean-atmosphere heat flux. This, in turn, feeds back onto the NAO to drive a reversal in NAO phase (to negative) which leads to a subsequent negative AMOC anomaly at 15-20 year lags. The integrated effect of long-term oscillatory signals in the $\mathrm{NAM}_{10}$ and the associated NAO variations may thus act as a metronome for the AMOC, which is a natural mode of oscillation in ocean circulation that varies on similar timescales. Further diagnosis of the separate impacts from intervals of persistent positive NAM (strong vortex) and persistent negative NAM (weak vortex with repeated SSW occurrences) showed that persistent strong vortex intervals had a much larger impact on the AMOC, perhaps not surprisingly because the vortex anomaly is consistently present throughout the whole winter.

We additionally found prominent non-stationary variations across multiple timescales in the AMOC, NAO and NAM 10 . Wavelet analysis revealed extended intervals in which 30, 50 and 90-year periodicities were dominant, so the composite response patterns were complicated by the superposition of contributions from intervals exhibiting different timescale behaviour. Interestingly, while all three indices ( $\mathrm{NAM}_{10}, \mathrm{NAO}$ and $\mathrm{AMOC}$ ) co-varied at the 30 and 50 yr periodicities, only the NAM 10 and AMOC co-varied at the 90yr periodicity and co-spectra analysis suggested that the AMOC leads the vortex signal. This suggests a feedback of the AMOC variability onto the vortex that does not involve the NAO. A recent study (DM21) using the same UKESM simulation found long-term (90yr) co-variability between the vortex and the QBO. This suggests the possibility that the 90yr AMOC-vortex relationship could act via an influence of the AMOC on equatorial wave forcing of the QBO, which then influences the vortex through the well-known Holton-Tan relationship. This was explored through wavelet and co-spectra analysis of variations in tropical east Pacific deep convection and QBO amplitude. These showed similar 90yr co-variability, indicating this as a plausible mechanism for the source of long-term variability in the QBO and the vortex, but further analysis of individual steps in the process, such as amplitude modulation of the various tropical waves that give rise to the QBO, would be required to confirm this.

Finally, we have applied the model results, that link a lagged AMOC response to the presence of persistent vortex anomalies, to assess the possible contribution of the interval of persistently strong vortex in the 1990s to the recent observed changes in the AMOC. Our analysis suggests a maximum AMOC response at 50N with a lag of approximately 17 years. The lagged vortex-AMOC relationship is statistically significant using the AMOC response at both $50 \mathrm{~N}(r=-0.908)$ and also at $30 \mathrm{~N}$ $(r=-0.652)$, the latter being closer in latitude to the RAPID Array observations. Using a regression technique we estimate that $-0.49 \mathrm{~Sv}$ of the observed RAPID Array AMOC trend by 2012 can be associated with the interval of persistent strong vortex behaviour centred on 1995. This represents nearly $17 \%$ of the total decrease in AMOC transport between 2005 and 2013 in the 
RAPID array data. The observed negative trend in the AMOC has been attributed to a range of factors, including the influence of anthropogenic forcings (Caesar et al., 2018, 2021), but to our knowledge, the potential role of vortex variability has not previously been considered. The origin of the interval of persistently strong vortex in the 1990s is unknown, but it was most likely due to internal variability. There is currently no consensus amongst climate models on how the vortex will respond to anthropogenic climate change (Ayarzagüena et al., 2020), and the 1990s appear to have been an anomalous period with no clear long-term trend emerging. As a result, our findings may indicate a significant role for internally generated signals in the recent negative AMOC trend.

665 There are several caveats to these results. Firstly, the results come from a single model, although there has also been limited analysis of vortex-AMOC interactions in CMIP5 models (Reichler et al. (2012). On the other hand, there is evidence that GCMs under-represent the influence of SSW events on the mid-latitude tropospheric jet, the NAO and surface temperatures, part of the "signal to noise" problem identified by Scaife and Smith (2018). Nevertheless, the model showed a clear NAO signal up to 3 months following vortex anomalies, indicating a reasonable representation of stratosphere - surface interaction. A previous study using the UKESM (DM21) also noted an underestimation of SSW frequency compared to the ERA-Interim dataset, which indicates a positive bias in the mean vortex strength as well as the $\mathrm{NAM}_{10}$, leading to the possible over-representation of positive $\mathrm{NAM}_{10}$ intervals. The variability in the AMOC may also be under-represented in the simulation, as Roberts et al. (2014) suggests that the models' decadal variability is smaller than that in the RAPID dataset. Additional analysis using a suite of CMIP6 models would clearly be useful to assess the robustness of the results presented here.

Composite and wavelet analysis of time series data presented here is effective for identifying co-variability between the stratosphere and ocean. However, these techniques are less capable of demonstrating causality within modes of variability and so additional targeted experiments would be useful to establish this. Nevertheless, we have suggested physical pathways for vortex-ocean interactions on multi-decadal timescales which rely on well-established teleconnections (e.g. the in-season vortex-NAO connection) and demonstrate a possible key role for these interactions in recent AMOC behaviour. Our results stress the role and importance of non-stationary signals for understanding long-term variability of the climate system. This complexity can be detrimental to analysis which relies on common stationary methods such as Fourier analysis. As a result, improved understanding and diagnosis of non-stationary climate variations as well as their underlying mechanisms will be key to overcoming these difficulties. 
Data availability.ERA5 reanalysis data are available from the Copernicus Climate Change Service Climate Data Store (CDS, https://climate.copernicus.eu/climate-reanalysis, C3S, 2017, last access: 10 August 2021). Data from the UKESM simulation used in this study are available from the Earth System Grid Federation of the Centre for Environmental Data Analysis (ESGF-CEDA;https://esgf-index1.ceda.ac.uk/projects/cmip6-ceda/,WRP,2019, last access: 6 August 2021). Author contributions. OBDM conducted the analyses, and LJG, SO, JR, RS and BS directed the research. All authors were fully involved in preparing and revising the text.

Competing interests. The authors declare that they have no conflict of interest.

Financial support. This research has been supported by the Natural Environment Research Council (grant no.

NE/L002612/1). Lesley Gray and Scott Osprey also receive funding from the UK Natural Environment Research Council (NERC) through the National Centre for Atmospheric Science (NCAS) ACSIS project (grant no. NE/N018001/1) and the NERC Belmont-Forum grant GOTHAM (grant no. NE/P006779/1). OBDM received support from the Oxford DTP in 695 Environmental Research (grant no. NE/L002612/1). JR was supported by NERC through NCAS, and through the NERC ACSIS project (NE/N018001/1), and the UKRI-NERC WISHBONE (NE/T013516/1) and SNAP-DRAGON (NE/T013494/1) projects. BS was supported by NOC ACSIS project (NE/N018044/1).

Acknowledgements. The authors would like to thank their respective funding bodies as well as Tim Woollings and Chris O'Reilly for useful discussions. We also give thanks to the UKESM1 team who have worked to develop and run the model used in this study as well as make the data available. In particular, Colin Jones, Jeremy Walton, Alistair Sellar and Till Kuhlbrodt. 


\section{References}

Alley, R. B.: Wally Was Right: Predictive Ability of the North Atlantic "Conveyor Belt" Hypothesis for Abrupt Climate Change, Annual Review of Earth and Planetary Sciences, 35, 241-272, https://doi.org/10.1146/annurev.earth.35.081006.131524, 2007.

Andrews, M. B., Knight, J. R., Scaife, A. A., Lu, Y., Wu, T., Gray, L. J., and Schenzinger, V.: Observed and Simulated Teleconnections Between the Stratospheric Quasi-Biennial Oscillation and Northern Hemisphere Winter Atmospheric Circulation, Journal of Geophysical Research: Atmospheres, 124, 1219-1232, https://doi.org/10.1029/2018JD029368, 2019.

Ayarzagüena, B., Palmeiro, F. M., Barriopedro, D., Calvo, N., Langematz, U., and Shibata, K.: On the Representation of Major Stratospheric Warmings in Reanalyses, Atmospheric Chemistry and Physics, 19, 9469-9484, https://doi.org/10.5194/acp-19-9469-2019, 2019.

Ayarzaguiena, B., Charlton-Perez, A., Butler, A., Hitchcock, P., Simpson, I., Polvani, L., Butchart, N., Gerber, E., Gray, L., Hassler, B., Lin, P., Lott, F., Manzini, E., Mizuta, R., Orbe, C., Osprey, S., Saint-Martin, D., Sigmond, M., Taguchi, M., and Watanabe, S.: Uncertainty in the Response of Sudden Stratospheric Warmings and Stratosphere-Troposphere Coupling to Quadrupled CO 2 Concentrations in CMIP6 Models, Journal of Geophysical Research: Atmospheres, 125, 103-121, https://doi.org/10.1029/2019JD032345, 2020.

Bakker, P., Schmittner, A., Lenaerts, J. T. M., Abe-Ouchi, A., Bi, D., van den Broeke, M. R., Chan, W.-L., Hu, A., Beadling, R. L., Marsland, S. J., Mernild, S. H., Saenko, O. A., Swingedouw, D., Sullivan, A., and Yin, J.: Fate of the Atlantic Meridional Overturning Circulation: Strong Decline under Continued Warming and Greenland Melting, Geophysical Research Letters, 43, 12,252-12,260, https://doi.org/10.1002/2016GL070457, 2016.

Baldwin, M. P. and Dunkerton, T. J.: Stratospheric Harbingers of Anomalous Weather Regimes, Science, 294, 581-584, https://doi.org/10.1126/science.1063315, 2001.

Baldwin, M. P., Ayarzagüena, B., Birner, T., Butchart, N., Butler, A. H., Charlton-Perez, A. J., Domeisen, D. I. V., Garfinkel, C. I., Garny, H., Gerber, E. P., Hegglin, M. I., Langematz, U., and Pedatella, N. M.: Sudden Stratospheric Warmings, Reviews of Geophysics, 59, e2020RG000 708, https://doi.org/10.1029/2020RG000708, 2021.

Bancalá, S., Krüger, K., and Giorgetta, M.: The Preconditioning of Major Sudden Stratospheric Warmings, Journal of Geophysical Research (Atmospheres), 117, 4101, https://doi.org/10.1029/2011JD016769, 2012.

Biastoch, A., Böning, C. W., Getzlaff, J., Molines, J.-M., and Madec, G.: Causes of Interannual-Decadal Variability in the Meridional Overturning Circulation of the Midlatitude North Atlantic Ocean, Journal of Climate, 21, 6599-6615, https://doi.org/10.1175/2008JCLI2404.1, 2008.

Böning, C. W., Scheinert, M., Dengg, J., Biastoch, A., and Funk, A.: Decadal Variability of Subpolar Gyre Transport and Its Reverberation in the North Atlantic Overturning, Geophysical Research Letters, 33, https://doi.org/10.1029/2006GL026906, 2006.

Buckley, M. W. and Marshall, J.: Observations, Inferences, and Mechanisms of the Atlantic Meridional Overturning Circulation: A Review, Reviews of Geophysics, 54, 5-63, https://doi.org/10.1002/2015RG000493, 2016.

Caesar, L., Rahmstorf, S., Robinson, A., Feulner, G., and Saba, V.: Observed Fingerprint of a Weakening Atlantic Ocean Overturning Circulation, Nature, 556, 191-196, https://doi.org/10.1038/s41586-018-0006-5, 2018.

Caesar, L., McCarthy, G. D., Thornalley, D. J. R., Cahill, N., and Rahmstorf, S.: Current Atlantic Meridional Overturning Circulation Weakest in Last Millennium, Nature Geoscience, 14, 118-120, https://doi.org/10.1038/s41561-021-00699-z, 2021.

Cessi, P., Bryan, K., and Zhang, R.: Global Seiching of Thermocline Waters between the Atlantic and the Indian-Pacific Ocean Basins, Geophysical Research Letters, 31, https://doi.org/10.1029/2003GL019091, 2004. 
Charlton, A. J. and Polvani, L. M.: A New Look at Stratospheric Sudden Warmings. Part I: Climatology and Modeling Benchmarks, Journal of Climate, 20, 449-469, https://doi.org/10.1175/JCLI3996.1, 2007.

Charlton-Perez, A. J., Ferranti, L., and Lee, R. W.: The Influence of the Stratospheric State on North Atlantic Weather Regimes, Quarterly Journal of the Royal Meteorological Society, 144, 1140-1151, https://doi.org/10.1002/qj.3280, 2018.

Cheng, H., Edwards, R. L., Broecker, W. S., Denton, G. H., Kong, X., Wang, Y., Zhang, R., and Wang, X.: Ice Age Terminations, Science, 326, 248-252, https://doi.org/10.1126/science.1177840, 2009.

Cohen, J., Barlow, M., and Saito, K.: Decadal Fluctuations in Planetary Wave Forcing Modulate Global Warming in Late Boreal Winter, Journal of Climate, 22, 4418-4426, https://doi.org/10.1175/2009JCLI2931.1, 2009.

Davini, P., Cagnazzo, C., and Anstey, J. A.: A Blocking View of the Stratosphere-Troposphere Coupling, Journal of Geophysical Research: Atmospheres, 119, 11,100-11,115, https://doi.org/10.1002/2014JD021703, 2014.

Delworth, T., Manabe, S., and Stouffer, R. J.: Interdecadal Variations of the Thermohaline Circulation in a Coupled Ocean-Atmosphere Model, Journal of Climate, 6, 1993-2011, https://doi.org/10.1175/1520-0442(1993)006<1993:IVOTTC>2.0.CO;2, 1993.

Delworth, T. L. and Dixon, K. W.: Implications of the Recent Trend in the Arctic/North Atlantic Oscillation for the North Atlantic Thermohaline Circulation, Journal of Climate, 13, 3721-3727, https://doi.org/10.1175/1520-0442(2000)013<3721:IOTRTI>2.0.CO;2, 2000.

Delworth, T. L. and Greatbatch, R. J.: Multidecadal Thermohaline Circulation Variability Driven by Atmospheric Surface Flux Forcing, Journal of Climate, 13, 1481-1495, https://doi.org/10.1175/1520-0442(2000)013<1481:MTCVDB>2.0.CO;2, 2000.

Delworth, T. L. and Mann, M. E.: Observed and Simulated Multidecadal Variability in the Northern Hemisphere, Climate Dynamics, 16, 661-676, https://doi.org/10.1007/s003820000075, 2000.

Delworth, T. L. and Zeng, F.: The Impact of the North Atlantic Oscillation on Climate through Its Influence on the Atlantic Meridional Overturning Circulation, Journal of Climate, 29, 941-962, https://doi.org/10.1175/JCLI-D-15-0396.1, 2016.

Dimdore-Miles, O., Gray, L., and Osprey, S.: Origins of Multi-Decadal Variability in Sudden Stratospheric Warmings, Weather and Climate Dynamics, 2, 205-231, https://doi.org/10.5194/wcd-2-205-2021, 2021.

Domeisen, D. I. V.: Estimating the Frequency of Sudden Stratospheric Warming Events From Surface Observations of the North Atlantic Oscillation, Journal of Geophysical Research: Atmospheres, 124, 3180-3194, https://doi.org/10.1029/2018JD030077, 2019.

Domeisen, D. I. V., Garfinkel, C. I., and Butler, A. H.: The Teleconnection of El Niño Southern Oscillation to the Stratosphere, Reviews of Geophysics, 57, 5-47, https://doi.org/10.1029/2018RG000596, 2019.

Domeisen, D. I. V., Butler, A. H., Charlton-Perez, A. J., Ayarzagüena, B., Baldwin, M. P., Dunn-Sigouin, E., Furtado, J. C., Garfinkel, C. I.,

Hitchcock, P., Karpechko, A. Y., Kim, H., Knight, J., Lang, A. L., Lim, E.-P., Marshall, A., Roff, G., Schwartz, C., Simpson, I. R., Son, S.-W., and Taguchi, M.: The Role of the Stratosphere in Subseasonal to Seasonal Prediction: 1. Predictability of the Stratosphere, Journal of Geophysical Research: Atmospheres, 125, e2019JD030 920, https://doi.org/10.1029/2019JD030920, 2020a.

Domeisen, D. I. V., Butler, A. H., Charlton-Perez, A. J., Ayarzagüena, B., Baldwin, M. P., Dunn-Sigouin, E., Furtado, J. C., Garfinkel, C. I., Hitchcock, P., Karpechko, A. Y., Kim, H., Knight, J., Lang, A. L., Lim, E.-P., Marshall, A., Roff, G., Schwartz, C., Simpson, I. R., Son, S.-W., and Taguchi, M.: The Role of the Stratosphere in Subseasonal to Seasonal Prediction: 2. Predictability Arising From StratosphereTroposphere Coupling, Journal of Geophysical Research: Atmospheres, 125, e2019JD030 923, https://doi.org/10.1029/2019JD030923, 2020b.

Eden, C. and Jung, T.: North Atlantic Interdecadal Variability: Oceanic Response to the North Atlantic Oscillation (1865-1997), Journal of Climate, 14, 676-691, https://doi.org/10.1175/1520-0442(2001)014<0676:NAIVOR>2.0.CO;2, 2001. 

2266-2280, https://doi.org/10.1175/1520-0442(2001)014<2266:MOITDV>2.0.CO;2, 2001.

Frankignoul, C., Gastineau, G., and Kwon, Y.-O.: The Influence of the AMOC Variability on the Atmosphere in CCSM3, Journal of Climate, 26, 9774-9790, https://doi.org/10.1175/JCLI-D-12-00862.1, 2013.

Frierson, D. M. W., Hwang, Y.-T., Fučkar, N. S., Seager, R., Kang, S. M., Donohoe, A., Maroon, E. A., Liu, X., and Battisti, D. S.: Contribution of Ocean Overturning Circulation to Tropical Rainfall Peak in the Northern Hemisphere, Nature Geoscience, 6, 940-944, https://doi.org/10.1038/ngeo1987, 2013.

Garfinkel, C. I., Hurwitz, M. M., and Oman, L. D.: Effect of Recent Sea Surface Temperature Trends on the Arctic Stratospheric Vortex, Journal of Geophysical Research: Atmospheres, 120, 5404-5416, https://doi.org/10.1002/2015JD023284, 2015.

Garfinkel, C. I., Son, S.-W., Song, K., Aquila, V., and Oman, L. D.: Stratospheric Variability Contributed to and Sustained the Recent Hiatus in Eurasian Winter Warming, Geophysical Research Letters, 44, 374-382, https://doi.org/10.1002/2016GL072035, 2017.

Gerber, E. P., Polvani, L. M., and Ancukiewicz, D.: Annular Mode Time Scales in the Intergovernmental Panel on Climate Change Fourth Assessment Report Models, Geophysical Research Letters, 35, https://doi.org/10.1029/2008GL035712, 2008a.

Gerber, E. P., Voronin, S., and Polvani, L. M.: Testing the Annular Mode Autocorrelation Time Scale in Simple Atmospheric General Circulation Models, Monthly Weather Review, 136, 1523-1536, https://doi.org/10.1175/2007MWR2211.1, 2008b.

Gerber, E. P., Orbe, C., and Polvani, L. M.: Stratospheric Influence on the Tropospheric Circulation Revealed by Idealized Ensemble Forecasts, Geophysical Research Letters, 36, https://doi.org/10.1029/2009GL040913, 2009.

Grinsted, A., Moore, J. C., and Jevrejeva, S.: Application of the Cross Wavelet Transform and Wavelet Coherence to Geophysical Time Series, Nonlinear Processes in Geophysics, 11, 561-566, https://doi.org/10.5194/npg-11-561-2004, 2004.

Haase, S., Matthes, K., Latif, M., and Omrani, N.-E.: The Importance of a Properly Represented Stratosphere for Northern Hemisphere Surface Variability in the Atmosphere and the Ocean, Journal of Climate, 31, 8481-8497, https://doi.org/10.1175/JCLI-D-17-0520.1, 2018.

Halpert, M. S. and Bell, G. D.: Climate Assessment for 1996, Bulletin of the American Meteorological Society, 78, S1-S50, https://doi.org/10.1175/1520-0477-78.5s.S1, 1997.

Hersbach, H., Bell, B., Berrisford, P., Hirahara, S., Horányi, A., Muñoz-Sabater, J., Nicolas, J., Peubey, C., Radu, R., Schepers, D., Simmons, A., Soci, C., Abdalla, S., Abellan, X., Balsamo, G., Bechtold, P., Biavati, G., Bidlot, J., Bonavita, M., Chiara, G. D., Dahlgren, P., Dee, D., Diamantakis, M., Dragani, R., Flemming, J., Forbes, R., Fuentes, M., Geer, A., Haimberger, L., Healy, S., Hogan, R. J., Hólm, E., Janisková, M., Keeley, S., Laloyaux, P., Lopez, P., Lupu, C., Radnoti, G., de Rosnay, P., Rozum, I., Vamborg, F., Villaume, S., and Thépaut, J.-N.: The ERA5 Global Reanalysis, Quarterly Journal of the Royal Meteorological Society, 146, 1999-2049, https://doi.org/10.1002/qj.3803, 2020.

Hitchcock, P. and Simpson, I. R.: The Downward Influence of Stratospheric Sudden Warmings, Journal of the Atmospheric Sciences, 71, 3856-3876, https://doi.org/10.1175/JAS-D-14-0012.1, 2014.

Hurrell, J., Kushnir, Y., Ottersen, G., and Visbeck, M.: The North Atlantic Oscillation: Climatic Significance and Environmental Impact, Geophys. Monogr. Ser., 134, https://doi.org/10.1029/GM134, 2003.

Johnson, N. C.: How Many ENSO Flavors Can We Distinguish?, Journal of Climate, 26, 4816-4827, https://doi.org/10.1175/JCLI-D-12$00649.1,2013$. 
King, A. D., Butler, A. H., Jucker, M., Earl, N. O., and Rudeva, I.: Observed Relationships Between Sudden Stratospheric Warmings and European Climate Extremes, Journal of Geophysical Research: Atmospheres, 124, 13 943-13 961, https://doi.org/10.1029/2019JD030480, 2019.

Knight, J. R., Allan, R. J., Folland, C. K., Vellinga, M., and Mann, M. E.: A Signature of Persistent Natural Thermohaline Circulation Cycles in Observed Climate, Geophysical Research Letters, 32, https://doi.org/10.1029/2005GL024233, 2005.

Kolstad, E. W., Breiteig, T., and Scaife, A. A.: The Association between Stratospheric Weak Polar Vortex Events and Cold Air Outbreaks in the Northern Hemisphere, Quarterly Journal of the Royal Meteorological Society, 136, 886-893, https://doi.org/10.1002/qj.620, 2010.

Kuhlbrodt, T., Griesel, A., Montoya, M., Levermann, A., Hofmann, M., and Rahmstorf, S.: On the Driving Processes of the Atlantic Meridional Overturning Circulation, Reviews of Geophysics, 45, https://doi.org/10.1029/2004RG000166, 2007.

Latif, M. and Keenlyside, N. S.: A Perspective on Decadal Climate Variability and Predictability, Deep Sea Research Part II: Topical Studies in Oceanography, 58, 1880-1894, https://doi.org/10.1016/j.dsr2.2010.10.066, 2011.

Lau, K.-M. and Weng, H.: Climate Signal Detection Using Wavelet Transform: How to Make a Time Series Sing, Bulletin of the American Meteorological Society, 76, 2391-2402, https://doi.org/10.1175/1520-0477(1995)076<2391:CSDUWT>2.0.CO;2, 1995.

Lavoie, D., Lambert, N., and Gilbert, D.: Projections of Future Trends in Biogeochemical Conditions in the Northwest Atlantic Using CMIP5 Earth System Models, Atmosphere-Ocean, 57, 18-40, https://doi.org/10.1080/07055900.2017.1401973, 2019.

Lawrence, Z. D., Perlwitz, J., Butler, A. H., Manney, G. L., Newman, P. A., Lee, S. H., and Nash, E. R.: The Remarkably Strong Arctic Stratospheric Polar Vortex of Winter 2020: Links to Record-Breaking Arctic Oscillation and Ozone Loss, Journal of Geophysical Research: Atmospheres, 125, e2020JD033 271, https://doi.org/10.1029/2020JD033271, 2020.

Lehtonen, I. and Karpechko, A. Y.: Observed and Modeled Tropospheric Cold Anomalies Associated with Sudden Stratospheric Warmings, Journal of Geophysical Research: Atmospheres, 121, 1591-1610, https://doi.org/10.1002/2015JD023860, 2016.

Liu, W., Xie, S.-P., Liu, Z., and Zhu, J.: Overlooked Possibility of a Collapsed Atlantic Meridional Overturning Circulation in Warming Climate, Science Advances, 3, e1601 666, https://doi.org/10.1126/sciadv.1601666, 2017.

Liu, W., Fedorov, A., and Sévellec, F.: The Mechanisms of the Atlantic Meridional Overturning Circulation Slowdown Induced by Arctic Sea Ice Decline, Journal of Climate, 32, 977-996, https://doi.org/10.1175/JCLI-D-18-0231.1, 2019.

835 Liu, Y., Liang, X. S., and Weisberg, R. H.: Rectification of the Bias in the Wavelet Power Spectrum, Journal of Atmospheric and Oceanic Technology, 24, 2093-2102, https://doi.org/10.1175/2007JTECHO511.1, 2007.

Lohmann, K., Drange, H., and Bentsen, M.: Response of the North Atlantic Subpolar Gyre to Persistent North Atlantic Oscillation like Forcing, Climate Dynamics, 32, 273-285, https://doi.org/10.1007/s00382-008-0467-6, 2009.

Lu, H., Baldwin, M. P., Gray, L. J., and Jarvis, M. J.: Decadal-Scale Changes in the Effect of the QBO on the Northern Stratospheric Polar Vortex, Journal of Geophysical Research: Atmospheres, 113, https://doi.org/10.1029/2007JD009647, 2008.

Lu, H., Bracegirdle, T. J., Phillips, T., Bushell, A., and Gray, L.: Mechanisms for the Holton-Tan Relationship and Its Decadal Variation, Journal of Geophysical Research: Atmospheres, 119, 2811-2830, https://doi.org/10.1002/2013JD021352, 2014.

Manney, G. L., Krüger, K., Sabutis, J. L., Sena, S. A., and Pawson, S.: The Remarkable 2003-2004 Winter and Other Recent Warm Winters in the Arctic Stratosphere since the Late 1990s, Journal of Geophysical Research: Atmospheres, 110, https://doi.org/10.1029/2004JD005367, 2005 .

Mantua, N. J., Hare, S. R., Zhang, Y., Wallace, J. M., and Francis, R. C.: A Pacific Interdecadal Climate Oscillation with Impacts on Salmon Production*, Bulletin of the American Meteorological Society, 78, 1069-1080, https://doi.org/10.1175/15200477(1997)078<1069:APICOW>2.0.CO;2, 1997. 
Manzini, E., Cagnazzo, C., Fogli, P. G., Bellucci, A., and Müller, W. A.: Stratosphere-Troposphere Coupling at Inter-Decadal Time Scales: Implications for the North Atlantic Ocean, Geophysical Research Letters, 39, https://doi.org/10.1029/2011GL050771, 2012.

Maycock, A. C., Masukwedza, G. I. T., Hitchcock, P., and Simpson, I. R.: A Regime Perspective on the North Atlantic Eddy-Driven Jet Response to Sudden Stratospheric Warmings, Journal of Climate, 33, 3901-3917, https://doi.org/10.1175/JCLI-D-19-0702.1, 2020.

McCarthy, G., Frajka-Williams, E., Johns, W. E., Baringer, M. O., Meinen, C. S., Bryden, H. L., Rayner, D., Duchez, A., Roberts, C., and Cunningham, S. A.: Observed Interannual Variability of the Atlantic Meridional Overturning Circulation at $26.5^{\circ} \mathrm{N}$, Geophysical Research Letters, 39, https://doi.org/10.1029/2012GL052933, 2012.

McCarthy, G. D., Smeed, D. A., Johns, W. E., Frajka-Williams, E., Moat, B. I., Rayner, D., Baringer, M. O., Meinen, C. S., Collins, J., and Bryden, H. L.: Measuring the Atlantic Meridional Overturning Circulation at $26^{\circ} \mathrm{N}$, Progress in Oceanography, 130, 91-111, https://doi.org/10.1016/j.pocean.2014.10.006, 2015.

Medhaug, I., Langehaug, H. R., Eldevik, T., Furevik, T., and Bentsen, M.: Mechanisms for Decadal Scale Variability in a Simulated Atlantic Meridional Overturning Circulation, Climate Dynamics, 39, 77-93, https://doi.org/10.1007/s00382-011-1124-z, 2012.

Menary, M. B., Park, W., Lohmann, K., Vellinga, M., Palmer, M. D., Latif, M., and Jungclaus, J. H.: A Multimodel Comparison of Centennial Atlantic Meridional Overturning Circulation Variability, Climate Dynamics, 38, 2377-2388, https://doi.org/10.1007/s00382-011-1172-4, 2012.

Menary, M. B., Kuhlbrodt, T., Ridley, J., Andrews, M. B., Dimdore-Miles, O. B., Deshayes, J., Eade, R., Gray, L., Ineson, S., Mignot, J., Roberts, C. D., Robson, J., Wood, R. A., and Xavier, P.: Preindustrial Control Simulations With HadGEM3-GC3.1 for CMIP6, Journal of Advances in Modeling Earth Systems, 10, 3049-3075, https://doi.org/10.1029/2018MS001495, 2018.

Mielke, C., Frajka-Williams, E., and Baehr, J.: Observed and Simulated Variability of the AMOC at $26^{\circ} \mathrm{N}$ and $41^{\circ} \mathrm{N}$, Geophysical Research Letters, 40, 1159-1164, https://doi.org/10.1002/grl.50233, 2013.

Moat, B. I., Frajka-Williams, E., Smeed, D., Rayner, D., Sanchez-Franks, A., Johns, W. E., Baringer, M. O., Volkov, D. L., and Collins, J.: Atlantic Meridional Overturning Circulation Observed by the RAPID-MOCHA-WBTS (RAPID-Meridional Overturning Circulation and Heatflux Array-Western Boundary Time Series) Array at 26N from 2004 to 2018 (V2018.2)., https://doi.org/10.5285/AA57E879-4CCA28B6-E053-6C86ABC02DE5, 2020.

Mulcahy, J. P., Jones, C., Sellar, A., Johnson, B., Boutle, I. A., Jones, A., Andrews, T., Rumbold, S. T., Mollard, J., Bellouin, N., Johnson, C. E., Williams, K. D., Grosvenor, D. P., and McCoy, D. T.: Improved Aerosol Processes and Effective Radiative Forcing in HadGEM3 and UKESM1, Journal of Advances in Modeling Earth Systems, 10, 2786-2805, https://doi.org/10.1029/2018MS001464, 2018.

Pawson, S. and Naujokat, B.: The Cold Winters of the Middle 1990s in the Northern Lower Stratosphere, Journal of Geophysical Research: Atmospheres, 104, 14 209-14 222, https://doi.org/10.1029/1999JD900211, 1999.

Rao, J., Garfinkel, C. I., and Ren, R.: Modulation of the Northern Winter Stratospheric El Niño-Southern Oscillation Teleconnection by the PDO, Journal of Climate, 32, 5761-5783, https://doi.org/10.1175/JCLI-D-19-0087.1, 2019.

Reichler, T., Kim, J., Manzini, E., and Kröger, J.: A Stratospheric Connection to Atlantic Climate Variability, Nature Geoscience, 5, 783-787, https://doi.org/10.1038/ngeo1586, 2012.

Ridley, J. K., Blockley, E. W., Keen, A. B., Rae, J. G. L., West, A. E., and Schroeder, D.: The Sea Ice Model Component of HadGEM3-GC3.1, Geoscientific Model Development, 11, 713-723, https://doi.org/10.5194/gmd-11-713-2018, 2018.

Roberts, C. D., Jackson, L., and McNeall, D.: Is the 2004-2012 Reduction of the Atlantic Meridional Overturning Circulation Significant?, Geophysical Research Letters, 41, 3204-3210, https://doi.org/10.1002/2014GL059473, 2014. 
Robson, J., Sutton, R., Lohmann, K., Smith, D., and Palmer, M. D.: Causes of the Rapid Warming of the North Atlantic Ocean in the Mid-1990s, Journal of Climate, 25, 4116-4134, https://doi.org/10.1175/JCLI-D-11-00443.1, 2012.

Robson, J., Aksenov, Y., Bracegirdle, T. J., Dimdore-Miles, O., Griffiths, P. T., Grosvenor, D. P., Hodson, D. L. R., Keeble, J., MacIntosh, C., Megann, A., Osprey, S., Povey, A. C., Schröder, D., Yang, M., Archibald, A. T., Carslaw, K. S., Gray, L., Jones, C., Kerridge, B., Knappett, D., Kuhlbrodt, T., Russo, M., Sellar, A., Siddans, R., Sinha, B., Sutton, R., Walton, J., and Wilcox, L. J.: The Evaluation of the North Atlantic Climate System in UKESM1 Historical Simulations for CMIP6, Journal of Advances in Modeling Earth Systems, 12, e2020MS002 126, https://doi.org/10.1029/2020MS002126, 2020.

Scaife, A. A. and Smith, D.: A Signal-to-Noise Paradox in Climate Science, npj Climate and Atmospheric Science, 1, 1-8, https://doi.org/10.1038/s41612-018-0038-4, 2018.

Schimanke, S., Zittel, J., Spangehl, T., and Cubasch, U.: Multi-Decadal Variability of Sudden Stratospheric Warmings in an AOGCM, Geophysical Research Letters - GEOPHYS RES LETT, 38, https://doi.org/10.1029/2010GL045756, 2011.

Shaw, T. A. and Perlwitz, J.: The Life Cycle of Northern Hemisphere Downward Wave Coupling between the Stratosphere and Troposphere, Journal of Climate, 26, 1745-1763, https://doi.org/10.1175/JCLI-D-12-00251.1, 2013.

Smeed, D., Moat, B. I., Rayner, D., Johns, W. E., Baringer, M. O., Volkov, D. L., and Frajka-Williams, E.: Atlantic Meridional Overturning Circulation Observed by the RAPID-MOCHA-WBTS (RAPID-Meridional Overturning Circulation and Heatflux Array-Western Boundary Time Series) Array at 26N from 2004 to 2018., https://doi.org/10.5285/8CD7E7BB-9A20-05D8-E053-6C86ABC012C2, 2019.

Smeed, D. A., Josey, S. A., Beaulieu, C., Johns, W. E., Moat, B. I., Frajka-Williams, E., Rayner, D., Meinen, C. S., Baringer, M. O., Bryden, H. L., and McCarthy, G. D.: The North Atlantic Ocean Is in a State of Reduced Overturning, Geophysical Research Letters, 45, 1527-1533, https://doi.org/10.1002/2017GL076350, 2018.

Storkey, D., Blaker, A. T., Mathiot, P., Megann, A., Aksenov, Y., Blockley, E. W., Calvert, D., Graham, T., Hewitt, H. T., Hyder, P., Kuhlbrodt, T., Rae, J. G. L., and Sinha, B.: UK Global Ocean GO6 and GO7: A Traceable Hierarchy of Model Resolutions, Geoscientific Model Development, 11, 3187-3213, https://doi.org/10.5194/gmd-11-3187-2018, 2018.

Sutton, R. T. and Hodson, D. L. R.: Atlantic Ocean Forcing of North American and European Summer Climate, Science, 309, 115-118, https://doi.org/10.1126/science.1109496, 2005.

910 Taguchi, M.: Is There a Statistical Connection between Stratospheric Sudden Warming and Tropospheric Blocking Events?, Journal of the Atmospheric Sciences, 65, 1442-1454, https://doi.org/10.1175/2007JAS2363.1, 2008.

Thompson, D. W. J., Baldwin, M. P., and Wallace, J. M.: Stratospheric Connection to Northern Hemisphere Wintertime Weather: Implications for Prediction, Journal of Climate, 15, 1421-1428, https://doi.org/10.1175/1520-0442(2002)015<1421:SCTNHW>2.0.CO;2, 2002.

Timmermann, A., An, S.-I., Krebs, U., and Goosse, H.: ENSO Suppression Due to Weakening of the North Atlantic Thermohaline Circulation, Journal of Climate, 18, 3122-3139, https://doi.org/10.1175/JCLI3495.1, 2005.

Tomassini, L., Gerber, E. P., Baldwin, M. P., Bunzel, F., and Giorgetta, M.: The Role of Stratosphere-Troposphere Coupling in the Occurrence of Extreme Winter Cold Spells over Northern Europe, Journal of Advances in Modeling Earth Systems, 4, https://doi.org/10.1029/2012MS000177, 2012.

Torrence, C. and Compo, G. P.: A Practical Guide to Wavelet Analysis., Bulletin of the American Meteorological Society, 79, 61-78, https://doi.org/10.1175/1520-0477(1998)079<0061:APGTWA>2.0.CO;2, 1998.

Tulloch, R. and Marshall, J.: Exploring Mechanisms of Variability and Predictability of Atlantic Meridional Overturning Circulation in Two Coupled Climate Models, Journal of Climate, 25, 4067-4080, https://doi.org/10.1175/JCLI-D-11-00460.1, 2012. 
Vial, J., Osborn, T., and Lott, F.: Sudden Stratospheric Warmings and Tropospheric Blockings in a Multi-Century Simulation of the IPSLCM5A Coupled Climate Model, Climate Dynamics, 40, https://doi.org/10.1007/s00382-013-1675-2, 2013.

Visbeck, M., Cullen, H., Krahmann, G., and Naik, N.: An Ocean Model's Response to North Atlantic Oscillation-like Wind Forcing, Geophysical Research Letters, 25, 4521-4524, https://doi.org/10.1029/1998GL900162, 1998.

Walters, D., Baran, A. J., Boutle, I., Brooks, M., Earnshaw, P., Edwards, J., Furtado, K., Hill, P., Lock, A., Manners, J., Morcrette, C., Mulcahy, J., Sanchez, C., Smith, C., Stratton, R., Tennant, W., Tomassini, L., Van Weverberg, K., Vosper, S., Willett, M., Browse, J., Bushell, A., Carslaw, K., Dalvi, M., Essery, R., Gedney, N., Hardiman, S., Johnson, B., Johnson, C., Jones, A., Jones, C., Mann, G., Milton, S., Rumbold, H., Sellar, A., Ujiie, M., Whitall, M., Williams, K., and Zerroukat, M.: The Met Office Unified Model Global Atmosphere 7.0/7.1 and JULES Global Land 7.0 Configurations, Geoscientific Model Development, 12, 1909-1963, https://doi.org/10.5194/gmd-121909-2019, 2019.

Wang, Z., Lu, Y., Dupont, F., W. Loder, J., Hannah, C., and G. Wright, D.: Variability of Sea Surface Height and Circulation in the North Atlantic: Forcing Mechanisms and Linkages, Progress in Oceanography, 132, 273-286, https://doi.org/10.1016/j.pocean.2013.11.004, 2015.

Wang, Z., Brickman, D., and Greenan, B. J. W.: Characteristic Evolution of the Atlantic Meridional Overturning Circulation from 1990 to 2015: An Eddy-Resolving Ocean Model Study, Deep Sea Research Part I: Oceanographic Research Papers, 149, 103 056, https://doi.org/10.1016/j.dsr.2019.06.002, 2019.

White, I. P., Garfinkel, C. I., Gerber, E. P., Jucker, M., Hitchcock, P., and Rao, J.: The Generic Nature of the Tropospheric Response to Sudden Stratospheric Warmings, Journal of Climate, 33, 5589-5610, https://doi.org/10.1175/JCLI-D-19-0697.1, 2020.

Williams, K. D., Copsey, D., Blockley, E. W., Bodas-Salcedo, A., Calvert, D., Comer, R., Davis, P., Graham, T., Hewitt, H. T., Hill, R., Hyder, P., Ineson, S., Johns, T. C., Keen, A. B., Lee, R. W., Megann, A., Milton, S. F., Rae, J. G. L., Roberts, M. J., Scaife, A. A., Schiemann, R., Storkey, D., Thorpe, L., Watterson, I. G., Walters, D. N., West, A., Wood, R. A., Woollings, T., and Xavier, P. K.: The Met Office Global Coupled Model 3.0 and 3.1 (GC3.0 and GC3.1) Configurations, Journal of Advances in Modeling Earth Systems, 10, 357-380, https://doi.org/10.1002/2017MS001115, 2018.

Xu, X., Chassignet, E. P., Johns, W. E., Schmitz, W. J., and Metzger, E. J.: Intraseasonal to Interannual Variability of the Atlantic Meridional Overturning Circulation from Eddy-Resolving Simulations and Observations, Journal of Geophysical Research: Oceans, 119, 5140-5159, https://doi.org/10.1002/2014JC009994, 2014.

Yang, J.: Local and Remote Wind Stress Forcing of the Seasonal Variability of the Atlantic Meridional Overturning Circulation (AMOC)

Transport at $26.5^{\circ} \mathrm{N}$, Journal of Geophysical Research: Oceans, 120, 2488-2503, https://doi.org/10.1002/2014JC010317, 2015.

Yool, A., Palmiéri, J., Jones, C. G., Sellar, A. A., de Mora, L., Kuhlbrodt, T., Popova, E. E., Mulcahy, J. P., Wiltshire, A., Rumbold, S. T., Stringer, M., Hill, R. S. R., Tang, Y., Walton, J., Blaker, A., Nurser, A. J. G., Coward, A. C., Hirschi, J., Woodward, S., Kelley, D. I., Ellis, R., and Rumbold-Jones, S.: Spin-up of UK Earth System Model 1 (UKESM1) for CMIP6, Journal of Advances in Modeling Earth Systems, 12, e2019MS001 933, https://doi.org/10.1029/2019MS001933, 2020.

955 Zhang, R.: Latitudinal Dependence of Atlantic Meridional Overturning Circulation (AMOC) Variations, Geophysical Research Letters, 37, https://doi.org/10.1029/2010GL044474, 2010. 


\section{Appendix A}

(a) AMOC $30 \mathrm{~N}$

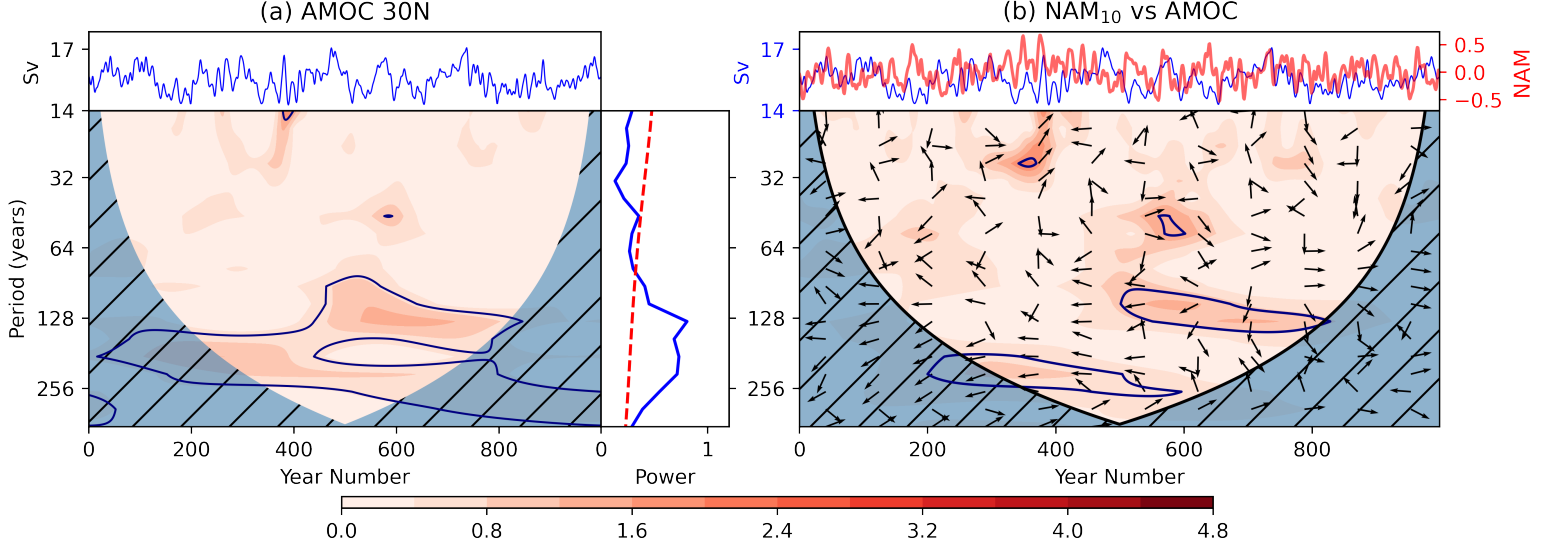

Figure A1. like figure 7 for the AMOC at 30 N. a shows the wavelet power spectrum of the NAO and $\mathbf{b}$ the cross power spectrum between the AMOC and the $\mathrm{NAM}_{10}$ index.

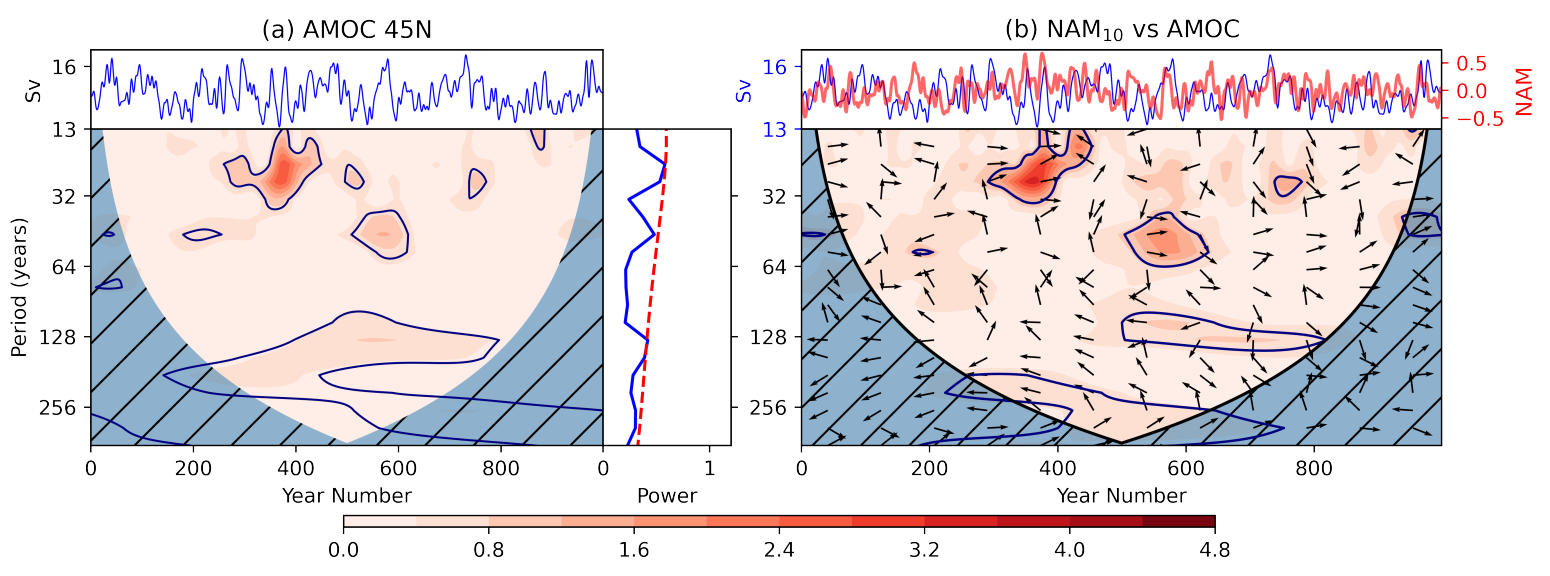

Figure A2. like figure 7 for the AMOC at $45 \mathrm{~N}$. a shows the wavelet power spectrum of the NAO and $\mathbf{b}$ the cross power spectrum between the AMOC and the $\mathrm{NAM}_{10}$ index. 

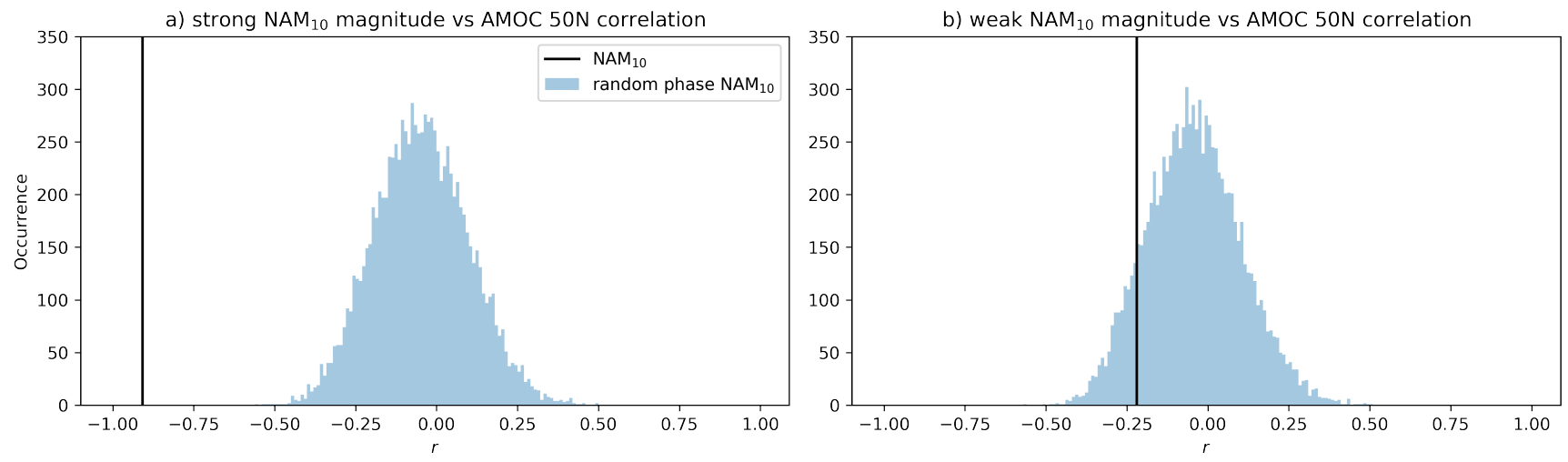

Figure A3. Probability distribution functions (PDFs) for correlations between the magnitude of NAM 10 extreme positive (a) and negative (b) values from surrogate $\mathrm{NAM}_{10}$ data and anomalies in the AMOC at $50 \mathrm{~N}$ evaluated 17 years later. Each NAM 10 surrogate is generated by applying a Fourier transform the smoothed $\mathrm{NAM}_{10}$ index, randomly shuffling the Fourier phases and inverse transforming. Each PDF is built with 10000 surrogates and the correlation between the $\mathrm{NAM}_{10}$ extreme magnitude and 17-year lagged AMOC anomaly at 50N is shown by vertical black lines in both subfigures. 